\title{
Active Polypropylene-Based Films Incorporating Combined Antioxidants and Antimicrobials: Preparation and Characterization
}

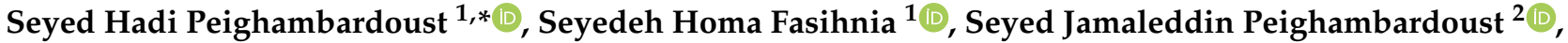 \\ Mirian Pateiro ${ }^{3}\left(\mathbb{D}\right.$, Rubén Domínguez ${ }^{3} \mathbb{D}$ and José M. Lorenzo $3,4, * \mathbb{C}$
}

Citation: Peighambardoust, S.H.; Fasihnia, S.H.; Peighambardoust, S.J.; Pateiro, M.; Domínguez, R.; Lorenzo, J.M. Active Polypropylene-Based Films Incorporating Combined

Antioxidants and Antimicrobials: Preparation and Characterization. Foods 2021, 10, 722. https: / /doi.org/10.3390/ foods 10040722

Academic Editors: Ana Sanches-Silva and Raquel Sendón

Received: 8 March 2021

Accepted: 26 March 2021

Published: 29 March 2021

Publisher's Note: MDPI stays neutral with regard to jurisdictional claims in published maps and institutional affiliations.

Copyright: (c) 2021 by the authors. Licensee MDPI, Basel, Switzerland. This article is an open access article distributed under the terms and conditions of the Creative Commons Attribution (CC BY) license (https:// creativecommons.org/licenses/by/ $4.0 /)$.
1 Department of Food Science, College of Agriculture, University of Tabriz, Tabriz 5166616471, Iran; h_fasihnia@tabrizu.ac.ir

2 Faculty of Chemical and Petroleum Engineering, University of Tabriz, Tabriz 5166616471, Iran; j.peighambardoust@tabrizu.ac.ir

3 Centro Tecnológico de la Carne de Galicia, Rúa Galicia N 4, Parque Tecnológico de Galicia, San Cibrao das Viñas, 32900 Ourense, Spain; mirianpateiro@ceteca.net (M.P.); rubendominguez@ceteca.net (R.D.)

4 Área de Tecnología de los Alimentos, Facultad de Ciencias de Ourense, Universidad de Vigo, 32004 Ourense, Spain

* Correspondence: peighambardoust@tabrizu.ac.ir (S.H.P.); jmlorenzo@ceteca.net (J.M.L.); Tel.: +98-41-3339-2052 (S.H.P.); +34-988-548-277 (J.M.L.)

\begin{abstract}
Development of polypropylene (PP) films incorporating antioxidant-antimicrobial agents can inhibit microbial growth and reduce undesirable deteriorating reactions and can preserve the quality of food. This study was aimed to use a combination of sorbic acid (SA), butylated hydroxyanisole (BHA), and butylated hydroxytoluene (BHT) to provide a synergistic effect at their reduced concentrations. A Combination of the additives was more effective in enhancing mechanical properties compared to their single state in film composition. The PP-2\%SA-3\%BHA film $\left(\mathrm{T}_{3}\right)$ had the highest tensile strength $(17.9 \mathrm{MPa})$ and the lowest elongation at break $(7.1 \%)$ than other films. The fourier-transform infrared (FTIR) proposed physical mixing of active additives within PP-matrix. Scanning electron microscopy showed uniform dispersion of the additives in PP-2\%SA$1 \%$ BHT-1\%BHA film $\left(\mathrm{T}_{4}\right)$ compared to others. BHT containing films decreased the storage and loss moduli leading to weakening of film viscoelastic behaviour and reducing film melting point. The prepared active films showed higher antioxidant activity than control PP-film following an order of $\mathrm{T}_{4}>\mathrm{T}_{2}>\mathrm{T}_{3}$ corresponding to DPPH radical scavenging values of $89.1,83.4$ and $79.1 \%$, respectively. All active films inhibited gram-negative and gram-positive bacteria growth. The results of this study indicated that the prepared active films possess desirable mechanical, thermal, antioxidant and antimicrobial properties enabling their use in food packaging.
\end{abstract}

Keywords: active packaging; polypropylene; BHA; BHT; sorbic acid; mechanical properties

\section{Introduction}

Microbial contamination and oxidation are two major factors deteriorating food quality after processing [1,2]. As a result, antimicrobial and antioxidant substances are being used to maintain food quality and extend the shelf-life of food products [3,4]. However, incautious use of chemical preservatives may show toxic effects in food products [5,6]. It has been reported that certain chemical preservatives show signs of genotoxicity when used at higher concentrations and may induce various type of chromosomal abnormalities [7]. In the food industry, synthetic antioxidants and antimicrobial substances are widely used to preserve products against oxidation reactions and microbial contaminations $[8,9]$. In an early report by Leslie et al. [10] it was shown that butylated hydroxyanisole (BHA) and butylated hydroxytoluene (BHT) can become cytotoxic leading to myocardial cultured 
cell injury and lysis at higher concentrations after long exposure time. In recent investigations, using flow cytometry analysis, the toxic effect of BHT on rat thymocytes cells was also proven [11]. Likewise, animal studies exhibited BHA-mediated liver toxicity and retardation in reproductive organ development [12]. As a result, the possible toxicity and carcinogenicity of synthetic antioxidants may counteract their direct consumption in food formulations [13].

Active packaging can minimize the direct use of chemical preservatives in food formulation, and thus, is gaining increased attention in extending food shelf-life [14-17]. A part from safety concerns mentioned above, from technological point of view, the direct application of antioxidant and antimicrobial agents to the bulk of food may hinder their activity because of possible interactions with other ingredients in food [18-22]. Hereof, designing active packaging films with controlled release of active substances could protect food from spoilage [23]. Besides, active films can favour reduction of additives concentrations, while offering the same level of protection, which can be achieved by direct incorporation of additives at higher concentrations [24-26]. Numerous synthetic or natural antioxidant agents [27-29] and sorbic acid (SA) [30] have been used in formulations of polymeric packaging materials to produce antioxidant and antimicrobial films.

Polypropylene (PP) is a conventional packaging material with extensive utilization due to its ease of processing and good barrier properties [31]. Compared to other synthetic polymers, PP benefits from higher resistance to chemicals, excellent mechanical properties, and stability upon high temperatures during film-making process. Therefore, PP is a suitable base for multifunctional food packaging films. Incorporating BHT and $\alpha$-tocopherol into PP and low-density polyethylene (LDPE) packaging films has shown that the resulting active films exhibited excellent retention of antioxidants upon storage time. That means that in the PP matrix, $\alpha$-tocopherol is released slowly, thus, its retention or active time will be longer in the polymeric matrix. Whereas some losses of antioxidants were observed in the case of LDPE matrix [32].

Many studies are reporting on the application of active LDPE/PP films with natural antioxidant such as quercetin and $\alpha$-tocopherol [33], green tea extract [34], Allium sativum essential oil [35]. Furthermore, LDPE active films containing synthetic antioxidants showed stability effect on linoleic acid [32], prevention of lipid oxidation in fish muscle [36], and odour stability in Asadero cheese [37]. Also, the antimicrobial effects of SA, or its salts, have been proved in a polymeric and biopolymeric matrix [38].

However, few researches have addressed the implementation of synthetic polymers such as PP to incorporate active agents for development of multifunctional active packaging. Development of functional packaging films, e.g., antioxidant-antimicrobial films, is one of the novel packaging areas to inhibit microbial growth and to prevent or reduce undesirable deteriorating reactions in order to maintain food quality and extend the shelflife of packaged foods. We previously designed PP-based antimicrobial films with sorbic acid [8] and antioxidant films containing BHT, BHA and TBHQ [39]. Those works only focused on incorporating single antimicrobial or antioxidant agents at different individual concentrations into the PP-matrix. The main focus of current study is the application of combined antioxidant-antimicrobial substances in the PP films and investigating the physical, mechanical, thermal, structural, antioxidant and antimicrobial properties of the obtained composite active films.

\section{Materials and Methods}

\subsection{Preparation of Active Films}

Polypropylene granules (Marun Petrochemical, Bandar-e-Emam, Iran), BHT and BHA (Merck, Darmstadt, Germany), and sorbic acid (AppliChem, Darmstadt, Germany) were formulated as shown in Table 1. The composite films were formulated based on the optimal amounts of active additives obtained in the previous experiments. First, we produced films containing 2, 4 and 6\% antimicrobial agents (sorbic acid) [8], then, 1, 2 and 3\% antioxidants (BHA, BHT and TBHQ) films [39]. Different physico-mechanical, thermal, 
structural, antioxidant/antimicrobial and migration properties of the obtained films were investigated. For this study, the composite films were separately prepared by combination of antioxidant and antimicrobial additives (as shown in Table 1) according to the procedure reported previously [40].

Table 1. The sample codes and formulation of active antioxidant/antimicrobial films.

\begin{tabular}{|c|c|c|c|c|}
\hline Film Samples & PP & $\begin{array}{c}\text { SA } \\
\text { (phr) }\end{array}$ & $\begin{array}{l}\text { BHT } \\
\text { (phr) }\end{array}$ & $\begin{array}{l}\text { BHA } \\
\text { (phr) }\end{array}$ \\
\hline Pure PP (control) $\left(\mathrm{T}_{1}\right)$ & 100 & - & - & - \\
\hline PP-2\%SA-1\%BHT $\left(\mathrm{T}_{2}\right)$ & 97 & 2 & 1 & - \\
\hline PP- $2 \%$ SA $-3 \%$ BHA $\left(\mathrm{T}_{3}\right)$ & 95 & 2 & - & 3 \\
\hline PP- $2 \%$ SA- $1 \%$ BHT- & & & & \\
\hline $\begin{array}{c}\text { 1\%BHA } \\
\left(\mathrm{T}_{4}\right)\end{array}$ & 96 & 2 & 1 & 1 \\
\hline
\end{tabular}

\subsection{Measurement of Film Properties}

\subsubsection{Thickness Measurement}

A digital micrometre (0-25 $\mathrm{mm}$ with an accuracy of $0.001 \mathrm{~mm}$, Mitutoyo, Japan) was used to measure film thickness. Triplicate measurements were performed at different locations of each film specimen $\left(10 \times 10 \mathrm{~cm}^{2}\right)$ taking a relaxation time of $2 \mathrm{~min}$ before the next measurement.

\subsubsection{Mechanical Properties}

Mechanical properties of the active films were evaluated by measuring the tensile strength (TS, MPa) and elongation at break $\left(\mathrm{E}_{\mathrm{b}}, \%\right)$ by ASTM D882-18 method [41] using a Tensile Machine (Cometech, Model QC-506B1, Taichung City, Taiwan) with a maximum load cell capacity of $10 \mathrm{kN}$. Film samples were cut into strips with a $10 \mathrm{~cm}$ length and $1 \mathrm{~cm}$ width. Tensile tests were carried out at the gauge distance and the rate of grip separation of $50 \mathrm{~mm}$ and $10 \mathrm{~mm} \cdot \mathrm{min}^{-1}$, respectively. Measurements were performed in triplicates. TS $(\mathrm{MPa})$ and $\mathrm{E}_{\mathrm{b}}(\%)$ were calculated using the following Equations (1) and (2),

$$
\begin{gathered}
T S=\frac{F_{\text {max }}}{A_{\min }} \\
E_{b}=\frac{L_{\max }}{L_{0}} \times 100
\end{gathered}
$$

where $F_{\text {max }}$ is the maximum extensional force, $A_{\text {min }}$ is the minimum cross-sectional area, $L_{\max }$ is amount of elongation at the rupture time, and $L_{0}$ is the initial length of film sample.

\subsubsection{Fourier-Transform Infrared (FTIR) Spectrum Analysis}

To determine possible interactions of functional groups between antioxidant additives with PP matrix, FTIR analysis was performed using a spectrophotometer (Bruker, Tensor 27 , Bremen, Germany) by scanning wavenumbers in a range of 4000 to $400 \mathrm{~cm}^{-1}$ at ambient temperature $\left(25^{\circ} \mathrm{C}\right)[42]$.

\subsubsection{Scanning Electron Microscopy (SEM)}

To study the cross-sectional microstructure of the composite films a scanning electron microscope (MIRA3, TESCAN, Brno, Czech Republic) was used with a rising voltage of 1 to $15 \mathrm{kV}$ with 20-fold magnification $[43,44]$. For SEM observations, a dry film samples were frozen in the liquid nitrogen for $10 \mathrm{~min}$ and then broken to produce a new cross-section followed by vacuum sputtering with a thin layer of gold. The best images were obtained at a voltage of $5 \mathrm{kV}$ and a $2 \mu \mathrm{m}$ scale [45]. 


\subsubsection{Dynamic Mechanical Thermal Analysis (DMTA)}

Dynamic mechanical and thermal properties of the active composite films were measured using a dynamic mechanical analyser (Triton Technology Ltd., model Tritec 2000 DMA, Keyworth, Nottinghamshire, UK) according to ASTM D5026 [46]. Samples were prepared in an approximate dimension of $9 \times 5 \times 0.026 \mathrm{~mm}^{3}$ (length $\times$ width $\times$ thickness) and tested at a temperature range of -50 to $150{ }^{\circ} \mathrm{C}$, a sinusoidal frequency of $1 \mathrm{~Hz}$, and $2{ }^{\circ} \mathrm{C} \mathrm{min}^{-1}$ temperature growths. Changes in storage (elastic or $\mathrm{E}^{\prime}$ ) and loss (viscous, $\mathrm{E}^{\prime \prime}$ ) moduli, as well as (loss factor $\left(\tan \delta, \mathrm{E}^{\prime \prime} / \mathrm{E}^{\prime}\right)$ were measured as a function of time and temperature. These properties provide insights on thermomechanical properties including glass transition temperature (Tg), damping behaviour, and effectiveness of cure [47].

\subsubsection{Film Transparency}

The transparency of a film sample relays on its light barrier properties. The relationship between the attenuation of light that falls on an observing medium and the properties of that medium can be explained by Beer-Lambert's law (Figure 1),

$$
A=\log \left(\frac{I_{0}}{I}\right)=\log \left(\frac{1}{T}\right)
$$

where $T$ is transmittance; $A$ is absorbance; $I_{0}$ and $I$ are the intensity of original light and of the transmitted light, respectively.

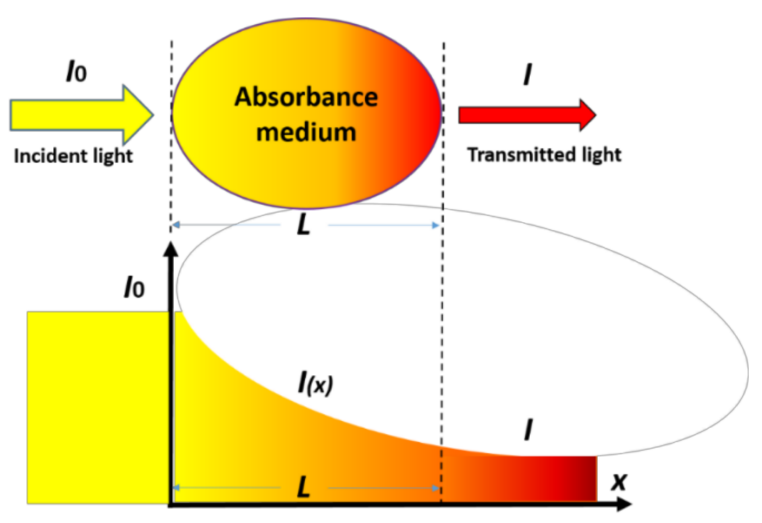

Figure 1. A schematic representation of Beer-Lambert's law to show relationship between the attenuation of incident light through an object the properties of that object, adopted from Sun and Chuang [48].

In this study, a double-beam spectrophotometer (SPECORD 250 PLUS, Jena, Germany) at a wavelength range between $200 \mathrm{~nm}$ and $800 \mathrm{~nm}$ was used to measure the UV and visible light barrier properties film samples [49]. The transparency determined by per cent of transmitted light through film specimen was calculated using light transmittance at wavelengths of $600 \mathrm{~nm}\left(\mathrm{~T}_{600}\right)$ from Equation (4), which was derived from Equation (3),

$$
T=-\log \frac{T_{600}}{X}
$$

where $T$ is the transparency of the samples, $T_{600}$ is $600 \mathrm{~nm}$ transmittance and $\mathrm{X}$ is the film thickness in $\mathrm{mm}$.

\subsubsection{Contact Angle}

To study the effect of additives used on the surface hydrophilic or hydrophobic characteristics of the polypropylene films, the contact angle of an adhesive droplet (Sessile drop) with film surface was measured. First, films were kept fixed on a plane glass surface by double-sided adhesive paper, and a small amount of distilled water $(2 \mu \mathrm{L})$ was placed on the surface of films to form a droplet. The contact angles were measured using ImageJ 
freeware with the plug-in Drop Shape Analysis with calculating the tangent angle at the three-phase (film-drop-air) contact point from the liquid side [50]. All data were performed in triplicate that each of them was the average of two angles of one droplet.

\subsubsection{Colour Measurement}

The colour properties of film samples, including total colour changes $(\Delta \mathrm{E})$, yellowness index (YI), and whiteness index (WI) were measured using a colorimeter simulator. In this device, the sample chamber is designed in a way that the angle of the camera and light source is $45^{\circ}$ at distance of $30 \mathrm{~cm}$ from the sample. Also, the chamber is insulated against environmental light. Film specimen $\left(10 \times 10 \mathrm{~cm}^{2}\right)$ were mounted on a white standard paper sheet to take photos using a digital camera with a 10-megapixel resolution (Canon, Japan). Lab mode of Adobe Photoshop software (CC 2014) was used to analyse colour parameters [51] according to the Equations (5)-(7),

$$
\begin{gathered}
\Delta E=\sqrt{\left(L_{S t}-L_{S m}\right)^{2}+\left(a_{S t}-a_{S m}\right)^{2}+\left(b_{S t}-b_{S m}\right)^{2}} \\
Y I=\frac{142.86 b}{L} \\
W I=100-\sqrt{(100-L)^{2}+a^{2}+b^{2}}
\end{gathered}
$$

where $\Delta E$ is total colour changes; $L, \mathrm{a}$, and b correspond to lightness, greenness/redness, and blueness/yellowness, respectively; $S t$ and $S m$ represent standard and sample, respectively; YI and WI are yellowness, and whiteness indices, respectively.

Triplicate measurements were performed in a way that each calculation was an average of five different locations.

\subsubsection{Antioxidant Capacity}

A search for proper antioxidant agents for food preservation is of interest for their economical usage in food formulations [52,53]. Antioxidant capacity of films can be measured by in situ methods [54]. However, DPPH (1,1-Diphenyl-2-Picrylhydrazyl) radical scavenging activity (RSA) measurement is by far the most commonly used method. To measure the antioxidant capacity, small pieces $(0.1 \mathrm{~g})$ of film samples were put in Falcon tubes containing $2 \mathrm{~mL}$ of methanol followed by shaking for $60 \mathrm{~s}$. The tubes were kept at ambient temperature for $2 \mathrm{~h}$ before analysis. A methanolic solution of DPPH ( $2 \mathrm{~mL} 0.1 \mathrm{mM})$ was then added to the methanol extract $(500 \mu \mathrm{L})$ followed by a vigorous shaking and keeping for $30 \mathrm{~min}$ at dark and ambient temperature. The mixture absorbance (A) was determined using a spectrophotometer (UNICO, UV-2100, Dayton, NJ, USA) at $517 \mathrm{~nm}$. To prepare the control sample the same procedure was performed, except that the film extract was replaced by methanol. DPPH RSA (\%) was obtained from the following Equation (8) [33]:

$$
\operatorname{RSA}(\%)=\left(1-\frac{\mathrm{A}_{\text {sample }}}{\mathrm{A}_{\text {control }}}\right) \times 100 \text {. }
$$

\subsubsection{In Vitro Antimicrobial Properties}

Escherichia coli (ATCC 25922), Staphylococcus aureus (ATCC 29523) and Aspergillus niger (ATCC 9029) were selected to assess the in-vitro antimicrobial activity of PP-based composite films according to the procedure explained in details earlier [40].

\subsubsection{Migration Behaviour}

British Standard EN 1186-1 [55] was used to measure the overall migration of additives in the films into different food simulants. Distilled water, acetic acid in water $(3 \% v / v)$ and ethanol in water were $(95 \% \mathrm{v} / \mathrm{v})$ considered as food simulants for aqueous foods ( $\mathrm{pH}>4.5)$, acidic foods ( $\mathrm{pH}<4.5)$, and fatty foods, respectively. Details of migration test was previously reported [40]. 


\subsection{Statistical Analyses}

A factorial design using Minitab 16 software was used to perform the statistical analysis. To determine any significant $(p<0.05)$ difference between the means the one-way ANOVA and Tukey's multiple range comparison test were carried out.

\section{Results and Discussion}

\subsection{Film Thickness}

The average thickness of the films was $25.63 \pm 0.25 \mu \mathrm{m}$. This value was considered for the calculations where the film thickness was needed.

\subsection{Mechanical Properties}

Figure 2 demonstrates the variation of tensile strength (TS) and elongation at break $\left(\mathrm{E}_{\mathrm{b}}\right)$ values of control film and composite active films containing either single (a) or a combination (b) of antioxidants/antimicrobial additives.

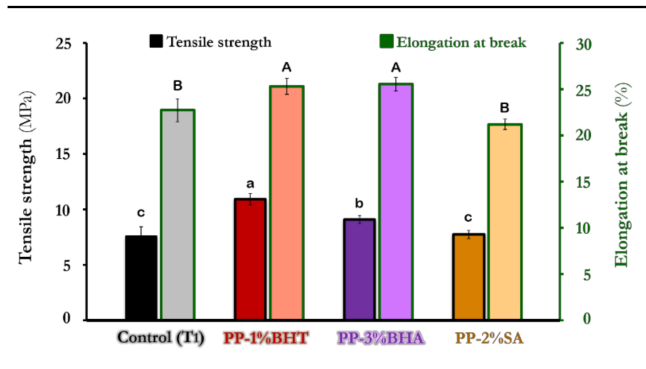

(a)

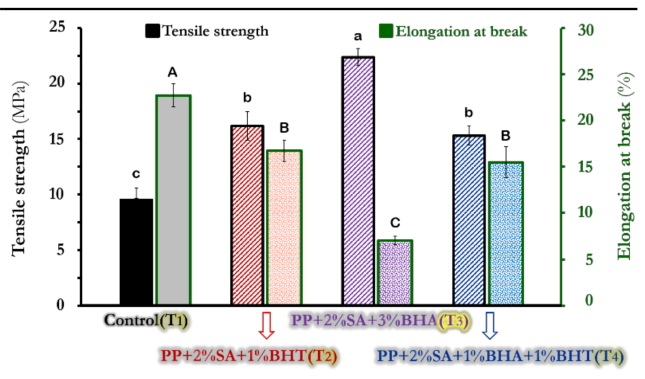

(b)

Figure 2. Tensile strength (TS) and elongation at break $\left(\mathrm{E}_{\mathrm{b}}\right)$ variations of pure polypropylene (PP) and different active composite films incorporating either single (a) or a combination (b) of antioxidants/antimicrobial substances. Data are mean of triplicate measurements. Error bars indicate SD values. Different small and capital letters show a significant $(p<0.05)$ difference between means for $\mathrm{TS}$ and $\mathrm{E}_{\mathrm{b}}$ parameters, respectively.

As shown in Figure 2a, TS and $\mathrm{E}_{\mathrm{b}}$ values of PP-1\%BHT and PP-3\%BHA were significantly $(p<0.05)$ higher than those of PP-2\%SA and control films, which PP-2\%SA film was not significantly different from control. The reason for observed differences among composite films may be attributed to different chemical structure and physical properties of incorporated additives (polarity, molar mass, molar volume and solubility), which could influence the interaction and compatibility of added substances with polymeric matrix $[45,56]$. This can influence mechanical properties of the composite films. The low polarity of BHT as compared with other additives (polarity: BHT $<$ BHA $<$ SA) may influence BHT compatibility with nonpolar polypropylene [57]. As a result, TS values of composite films followed an order of PP-BHT $>$ PP-BHA $>$ PP-SA (Figure 2a). Besides, the order of molar mass and molar volume was BHT $>$ BHA $>$ SA (Table 2), which may enhance the interaction of larger additives with polymeric matrix. As a result, this can increase TS and $E_{b}$ values of the resulting films. Decreased TS and $E_{b}$ values of $S A$ films compared to those of BHT and BHA films is may be due to the fact that SA is more polar and has lower molar mass compared to BHT and BHA, which this may decrease its compatibility with PP matrix. 
Table 2. Chemical structure and physical properties of SA, BHA and BHT.

\begin{tabular}{cccc}
\hline & $\mathbf{S A}$ & $\mathbf{B H A}$ & $\mathbf{B H T}$ \\
\hline Chemical structure & $\mathbf{C}_{\mathbf{6}} \mathbf{H}_{\mathbf{8}} \mathbf{O}_{\mathbf{2}}$ & $\mathbf{C}_{\mathbf{1 1}} \mathbf{H}_{\mathbf{1 6}} \mathbf{O}_{\mathbf{2}}$ & $\mathbf{C}_{\mathbf{1 5}} \mathbf{H}_{\mathbf{2 4}} \mathbf{O}$ \\
\cline { 2 - 4 } & & & \\
Density $\left(\mathrm{g} \cdot \mathrm{cm}^{-3}\right)$ & 1.204 & 1.06 & 1.048 \\
Solubility in water $\left(\mathrm{g} \cdot \mathrm{L}^{-1}\right)$ & 1.6 & 0 & 1.1 \\
Solubility in ethanol $\left(\mathrm{g} \cdot \mathrm{L}^{-1}\right)$ & 12.9 & Freely soluble & Freely soluble \\
Molar mass $\left(\mathrm{g} \cdot \mathrm{mol}^{-1}\right)$ & 112.1 & 180.2 & 220.4 \\
Molar volume $\left(\mathrm{cm}^{3} \cdot \mathrm{mol}^{-1}\right)$ & 109.4 & 182.4 & 256.0 \\
Polarity & High & Medium & Low \\
\hline
\end{tabular}

As shown in Figure 2b, BHA leads to higher tensile strength in combinatory films. PP-2\%SA-3\%BHA $\left(\mathrm{T}_{3}\right)$ showed the highest TS $(17.91 \mathrm{MPa})$ and the lowest $\mathrm{E}_{\mathrm{b}}(7.1 \%)$ values, followed by $T_{2}$ and $T_{4}$ films, which was not significantly different from each other. It seems that, on one hand, the higher concentrations of BHA, and the possible synergistic effect of SA with BHA, on the other hand, can result in significantly $(p<0.05)$ increased TS and reduced $E_{b}$ values for $T_{3}$ sample. $T_{2}$ and $T_{4}$ films had similarly higher TS, but lower $E_{b}$ values than control. Besides, comparing all combinatory composite films $\left(\mathrm{T}_{2}-\mathrm{T}_{4}\right)$ (Figure $2 \mathrm{~b}$ ) with those containing individual additives (Figure 2a) reveals that combinatory composite films reveal improved mechanical properties. These results may be explained by possible synergism between dispersed particles in combinatory films. It can be concluded that by combining two or three additives at low concentrations, the same, or even improved, mechanical properties of the film can be obtained.

\subsection{Fourier-Transform Infrared (FTIR) Spectrum}

FTIR spectra (absorbance \% vs. wavenumber or frequency) of BHT, BHA and SA at a wavenumber range of $400-4000 \mathrm{~cm}^{-1}$ are presented in Figure 3. BHT's characteristic absorption peaks (Figure 3A) were at $3628 \mathrm{~cm}^{-1}(\mathrm{O}-\mathrm{H}$ stretching mode of vibration in phenol ring), $3068 \mathrm{~cm}^{-1}$ (C-H stretching), $2956 \mathrm{~cm}^{-1}$ (asymmetric vibrations of methyl group), $2872 \mathrm{~cm}^{-1}$ (symmetric stretching vibrations of methyl group), $1603 \mathrm{~cm}^{-1}$ (C=C bonds stretching), $1439 \mathrm{~cm}^{-1}$ ( $\mathrm{CH}_{3}$ bending vibrations), $1361 \mathrm{~cm}^{-1}$ (tert-butyl bending), $1230 \mathrm{~cm}^{-1}$ (in plane $\mathrm{C}-\mathrm{H}$ bending), $1151 \mathrm{~cm}^{-1}$ (in plane $\mathrm{O}-\mathrm{H}$ bending), $1026 \mathrm{~cm}^{-1}\left(-\mathrm{CH}_{3}\right.$ rocking vibration), 866 and $769 \mathrm{~cm}^{-1}$ (C-C stretching), and $580 \mathrm{~cm}^{-1}$ (out of plane phenol ring bending) [56,58-61]. Also, FTIR analysis revealed the characteristic peaks for BHA (Figure 3B) at wavenumbers ( $\mathrm{cm}^{-1}$ ) of 3395 (O-H bound stretching), 2952 (C-H stretching), 1506 (phenyl ring), 414 (bending of $-\mathrm{CH}_{2}$ adjacent to the phenyl), 1365 (bending of $-\mathrm{CH}_{2}$ adjacent to the phenyl) and 1033 (C-O bond stretching), and 815, 765, and 679 (bending of $\mathrm{C}=\mathrm{C}$ out of plane phenol ring) [62-65]. Sorbic acid (Figure 3C) showed absorption peaks at wavenumbers $\left(\mathrm{cm}^{-1}\right)$ of 2963 to $2560(\mathrm{O}-\mathrm{H}$ bond stretching modes in a carboxylic acid), 1690 ( $\mathrm{C}=\mathrm{O}$ stretching), 1630 ( $\mathrm{C}=\mathrm{C}$ stretching), 1421 (C-C stretching), 1322 (C-O stretching), 1262 ( $-\mathrm{CH}_{3}$ rocking vibration), 1000 and 924 (C-C stretching), and 695 to 462 ( $\mathrm{C}=\mathrm{C}$ bending) $[40]$. 

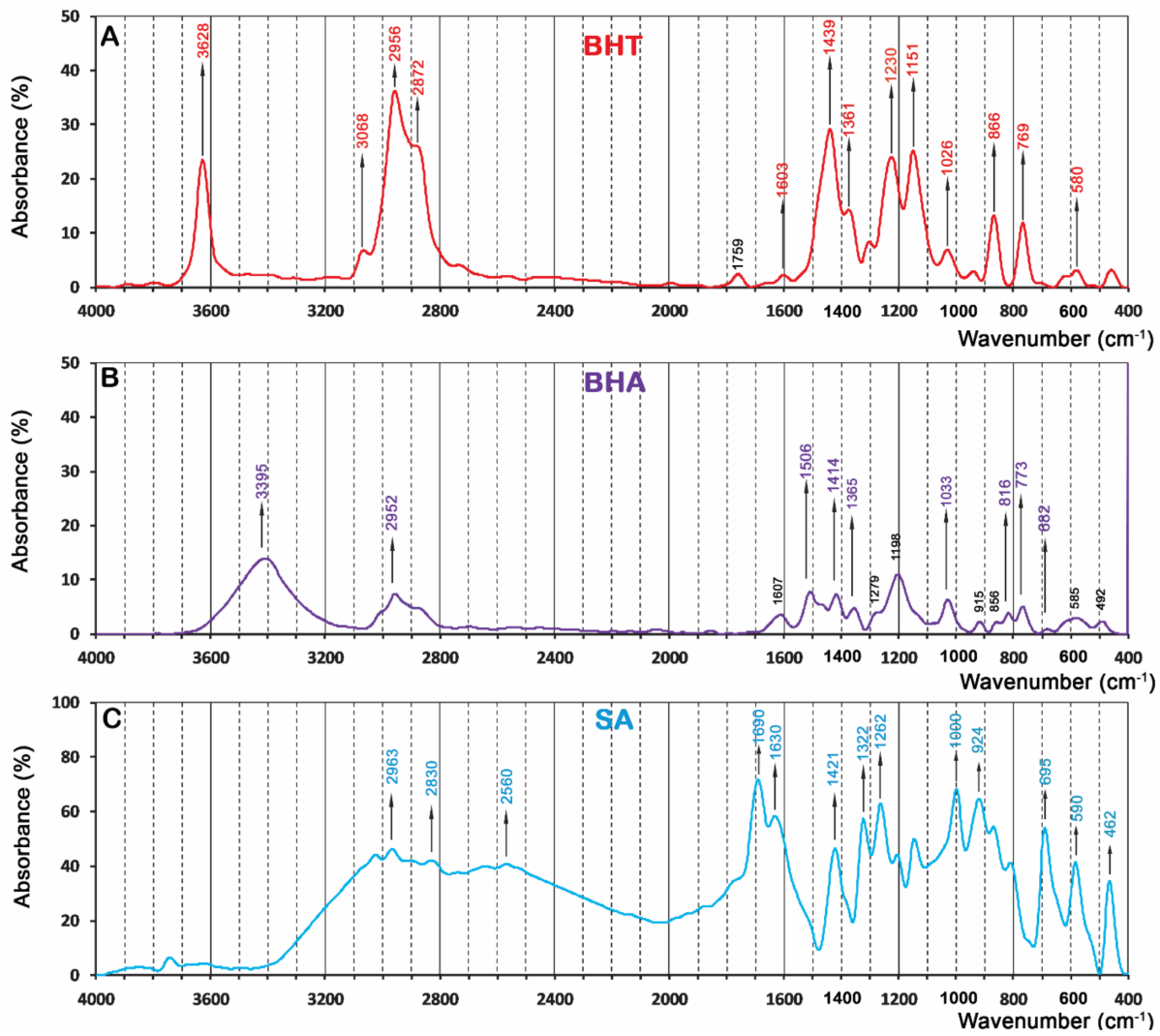

Figure 3. FTIR spectra of butylated hydroxytoluene, BHT (A); butylated hydroxyanisole, BHA, (B); and sorbic acid, SA (C).

FTIR spectra of pure polypropylene (control, $\mathrm{T}_{1}$ ), PP-2\%SA- $1 \% \mathrm{BHT}\left(\mathrm{T}_{2}\right), \mathrm{PP}-2 \% \mathrm{SA}-$ $3 \%$ BHA $\left(\mathrm{T}_{3}\right)$ and PP-2\%SA-1\%BHT-1\%BHA $\left(\mathrm{T}_{4}\right)$ packaging films are shown in Figure 4. Pure PP film as well as active composite films exhibited characteristic absorption peaks at $2960 \mathrm{~cm}^{-1}$ (C-H stretching), $2836 \mathrm{~cm}^{-1}$ (asymmetric $-\mathrm{CH}_{3}$ group's vibration), $2723 \mathrm{~cm}^{-1}$ (C-H out of the plane bending), $1456 \mathrm{~cm}^{-1}$ (deformation of the $-\mathrm{CH}_{2}$ bond), $1376 \mathrm{~cm}^{-1}$ (symmetric $-\mathrm{CH}_{3}$ group's vibration), $1167 \mathrm{~cm}^{-1}$ (C-C bending related to the backbone of polypropylene), 998 and $842 \mathrm{~cm}^{-1}$ (isotactic polypropylene band) [59]. 


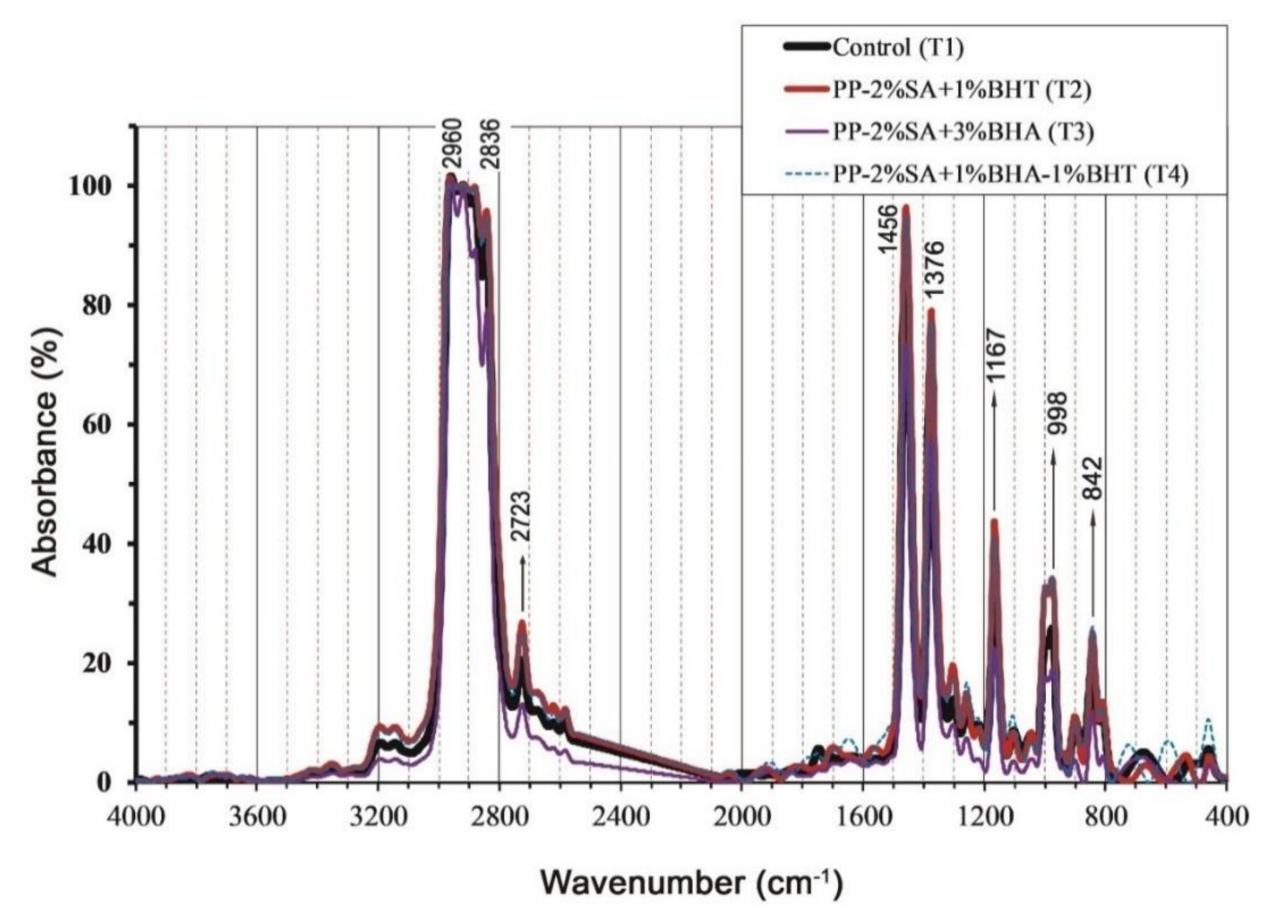

Figure 4. FTIR spectra of pure polypropylene (control, $\mathrm{T}_{1}$ ), PP-2\%SA-1\%BHT $\left(\mathrm{T}_{2}\right), \mathrm{PP}-2 \% \mathrm{SA}-3 \% \mathrm{BHA}$ $\left(\mathrm{T}_{3}\right)$ and PP-2\%SA-1\%BHT-1\%BHA $\left(\mathrm{T}_{4}\right)$ packaging films.

The results of FTIR spectra of composite active films as compared to the control (pure PP) film is shown in Figure 4. As can be seen in this figure, the main components of the FTIR spectrum were detected for all composite films indicating that incorporating BHT, BHA or SA into PP matrix did not lead to significant changes (formation or deletion of new chemical bonds) in the functional groups of PP film. It can be concluded that production of composite films via extrusion process this process leads to physical mixing rather than chemical modification. Similar results were reported by Kang et al. [59] for BHA and BHT, indicating that there is no certain chemical interaction between BHT and PP matrix, thereby, the mixing was mostly physical. From these results, we can speculate that the antioxidants/antimicrobial substances incorporated into the PP matrix have enough mobility to migrate from the film surface into packaged materials.

\subsection{Scanning Electron Microscopy (SEM)}

Scanning electron microscopy is one of the most powerful tools used in various disciplines, with the help of electron bombardment to provide small objects of $10 \mathrm{~nm}$ images for study. The SEM images of the produced film samples in a length-scale of 2 $\mu \mathrm{m}$ are shown in Figure 5. The images obtained from the cross-fracture surface of the polypropylene control film (4a) indicated a relatively smooth surface compared to other samples, which is in agreement with Singh et al. [66]. The image $4 \mathrm{~b}$ represented the surface obtained from the PP-2\%SA-1\%BHT film $\left(\mathrm{T}_{2}\right)$, which shows both dispersed (yellow arrows) and agglomerated particles (dotted circles and white arrows) of active additives in the polymeric matrix (PP in the figures) showing uneven and coarse cross-section surface of the film. In Figure $5 c, d$, the background of the polypropylene with visible dispersion of large and small are clearly seen. Among three active film samples, PP-2\%SA-1\%BHT-1\%BHA $\left(\mathrm{T}_{4}\right)$ sample had the most homogenous dispersion of the particles. In the SEM images, it is clear that all particles in the matrix have a size smaller than $0.5 \mu \mathrm{m}$, and it seems that the coarse particles (white arrows) are related to SA and the finer particles (yellow arrows) represented antioxidant particles. Since BHA and BHT are melted at temperatures of $48^{\circ} \mathrm{C}$, and $70^{\circ} \mathrm{C}$, respectively (early stages of the film preparation) they are uniformly dispersed in the polymeric matrix (PP) due to the similarity of their structure (lower polarity) with that of the base polymer and appear as fine particles in the SEM images 
(yellow arrows in Figure 5c). These results are in conflict with those of Goncalves et al. [67], who reported coarse particles of BHT antioxidant in PLA matrix. On the other side, SA has a higher melting point $\left(135^{\circ} \mathrm{C}\right)$ and polarity which results in the lack of compatibility with non-polar PP, hence it may not be melted entirely during film preparation. Similar to Kuplennik et al. [38], where they incorporated potassium sorbate in LLDPE matrix, formed agglomerates led to coarser particles in the matrix.
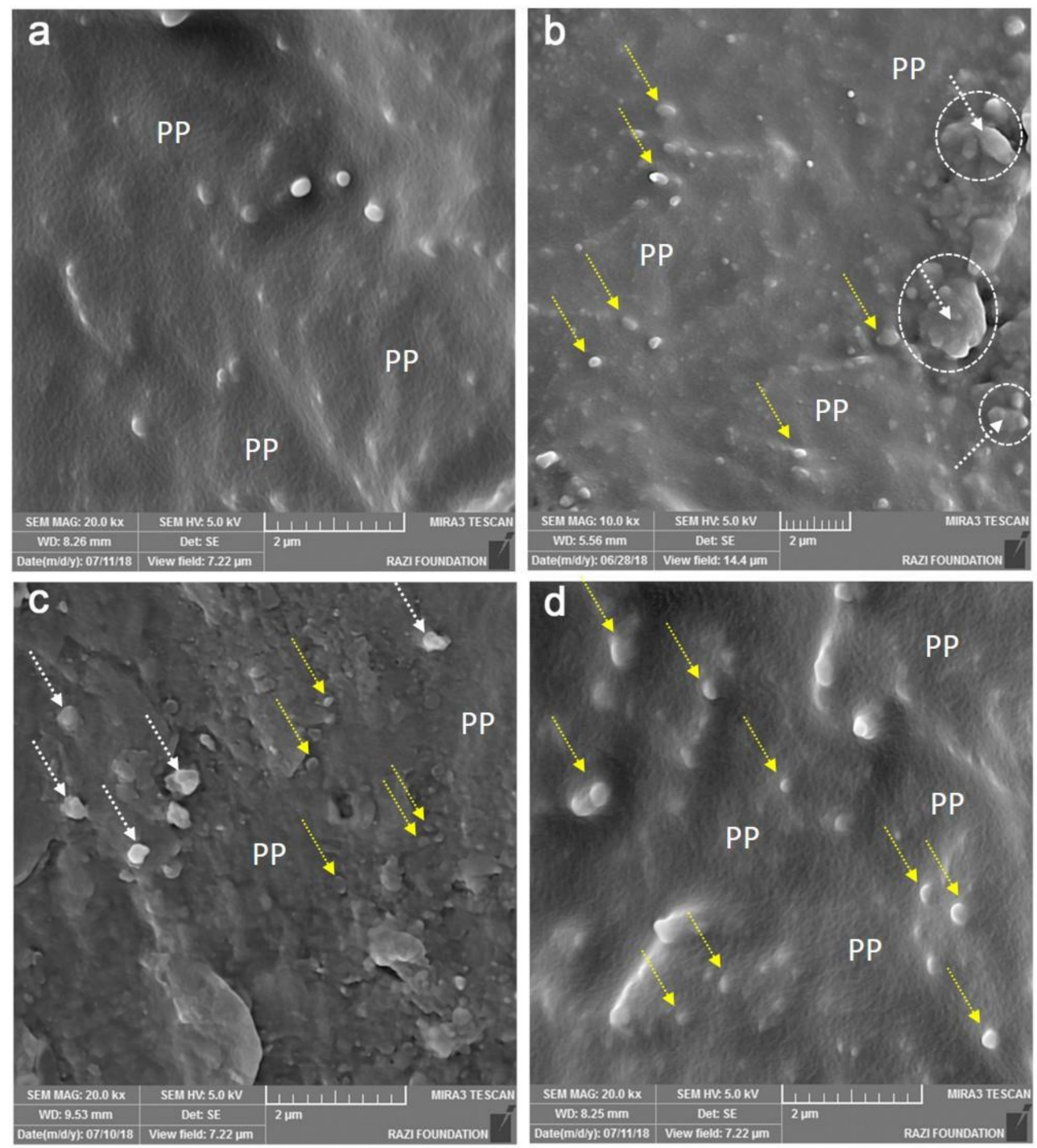

Figure 5. SEM images of pure PP film (control) (a) and active composite films: PP- $2 \% \mathrm{SA}-1 \% \mathrm{BHT}$ (b); PP-2\%SA-3\%BHA (c); PP-2\%SA-1\%BHT-1\%BHA (d).

\subsection{Dynamic Mechanical Thermal Analysis (DMTA)}

The viscoelastic behaviour of prepared films was tested by DMTA, as well as the measuring glass transition temperature (Tg). The results were shown as a storage modulus $\left(\mathrm{E}^{\prime}\right)$, a loss modulus $\left(\mathrm{E}^{\prime \prime}\right)$ and a loss factor or damping coefficient $(\tan \delta)$ as a function of temperature (Figure 6). The $\mathrm{E}^{\prime}$ relates to the elasticity of the material and is an indicator of its ability to store energy. The $\mathrm{E}^{\prime}$ changes for pure $\mathrm{PP}$ and composite films as a function of temperature (in the range of -50 to $150{ }^{\circ} \mathrm{C}$ ) are presented in Figure 6A. As can be seen in this figure, the $\mathrm{E}^{\prime}$ of pure PP film $\left(\mathrm{T}_{1}\right)$ was the highest $(1620 \mathrm{MPa})$ at the test temperature range, and then gradually decreased with increasing the temperature up to $18{ }^{\circ} \mathrm{C}$ followed by a sharp decrease. There was an initial increase in the $\mathrm{E}^{\prime}$ of the PP- $2 \% \mathrm{SA}+1 \% \mathrm{BHT}$ film at the similar temperature as $\mathrm{Tg}$ of the composite. This observation was probably due to 
the accumulation of large BHT crystals, which, in less than Tg of the composite film, the stress is locked until to reach a sufficient fluidity, and by approaching this temperature, it is provided possibility to move the polymer chains by releasing their trapped energy [38].

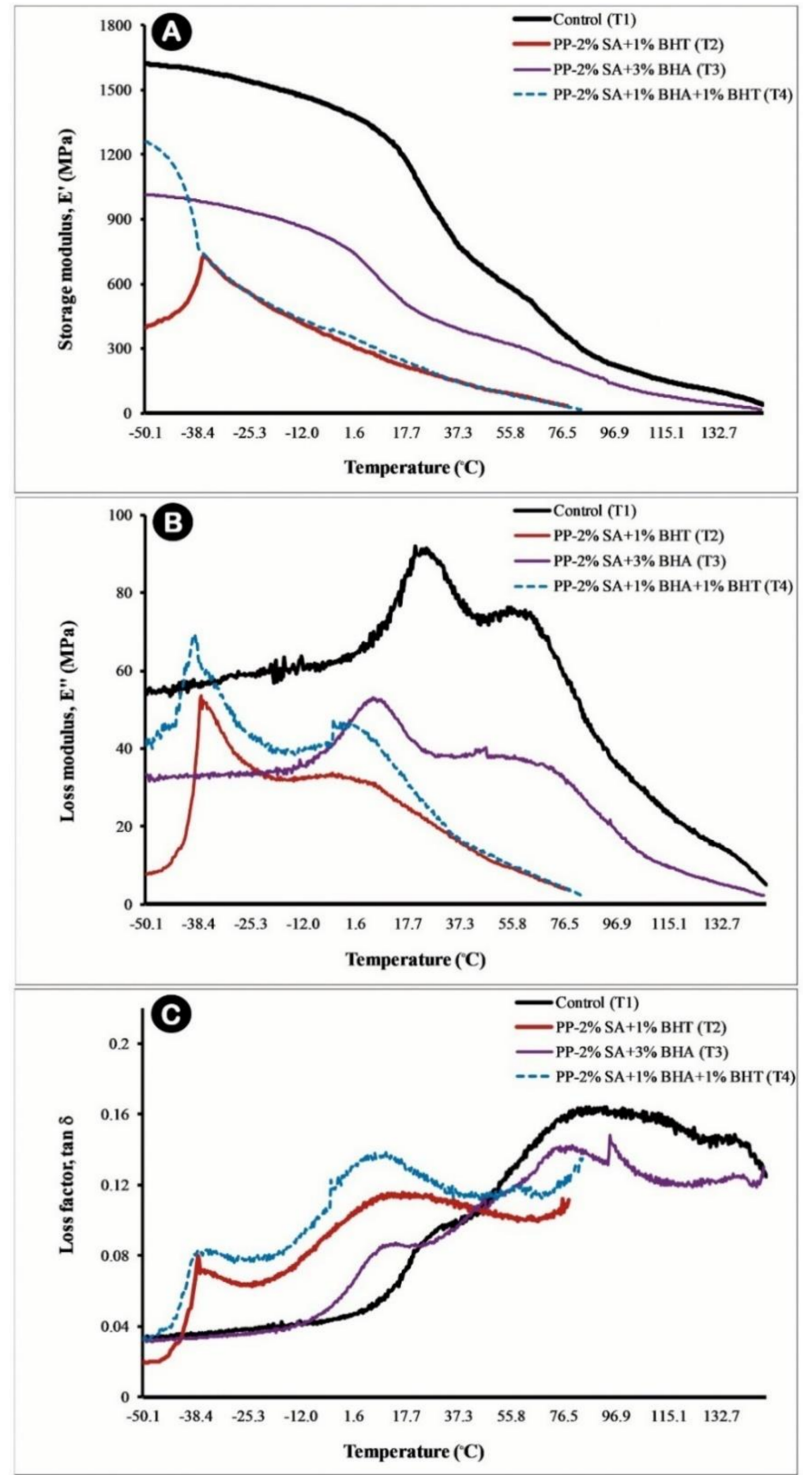

Figure 6. Viscoelastic behaviour for pure polypropylene (control, $\mathrm{T}_{1}$ ) and different active composite films $\left(\mathrm{T}_{2}-\mathrm{T}_{4}\right)$ as measured by storage modulus, $\mathrm{E}^{\prime}(\mathbf{A})$; loss modulus, $\mathrm{E}^{\prime \prime}(\mathbf{B})$; and loss factor. tan $\delta,(\mathrm{C})$.

The E" is an indicator of the viscosity of the films and represents the amount of energy lost by the system. As displayed in Figure 6B, in all samples, with increasing temperature, the E" increased, and after presenting two peaks, dropped again. The sharp 
increase in the E" indicated more mobility of the polymer structure because of the glass transition of rubber that was not feasible at temperatures lower than $\mathrm{Tg}$. In the studied temperature range, two transition stages were well observed. The first peak was observed for samples containing $\mathrm{BHT}$ at temperatures from -37 to $-39^{\circ} \mathrm{C}$, which was related to the $\beta$-transition and Tg. In the $\mathrm{T}_{3}$ (PP-2\%SA-3\%BHA) and $\mathrm{T}_{4}$ (PP-2\%SA-1\%BHT-1\%BHA) samples (containing 3 and $1 \% \mathrm{BHA}$ ), Tg peaks were depicted at temperatures of 6.7 and $-3.9^{\circ} \mathrm{C}$, respectively, which was significantly lower than $\mathrm{Tg}$ of pure PP film $\left(25.6^{\circ} \mathrm{C}\right)$. As it could be seen, the shifting of the Tg to lower temperatures could be attributed to the presence of BHT and BHA antioxidants in the polymer matrix, which increased the mobility of polymer chains and accelerated the transition process. The DMTA pattern of PP displayed a second peak at a temperature of $54{ }^{\circ} \mathrm{C}$, which was related to the $\alpha$ transition. This transition was identified as the depreciation of the amorphous polymer chains energy and was found in semi-crystalline polymers [68]. Due to the presence of active materials, the temperature range of the transition was narrowed, which resulted in rising the mobility of polymer chains. Incorporating antioxidant and antimicrobial agents to the PP matrix decreased the peak height of the E" curve, which was due to the lowering of internal friction, and which indicated a decrease in mechanical energy dissipation [68].

The loss factor $(\tan \delta)$ is attributed to the equilibrium between the elastic and viscous phase of the material and depends on the mobility of the polymer structure. Based on Figure $6 \mathrm{C}, \tan \delta$ of polypropylene and composites was affected by additives. In a composite containing 3\% BHA, the loss factor was less than pure PP polymer at temperatures higher than $47^{\circ} \mathrm{C}$. This could be attributed to limited movement of polymer molecules in the presence of BHA. At temperatures below $47^{\circ} \mathrm{C}$, the addition of BHT increased the loss factor of $T_{2}$ and $T_{4}$ composites. This increase was clearly seen in Figure $6 \mathrm{C}$, which referred to the higher movement range of polymer molecules in the presence of BHT, especially the presence of both antioxidants [69]. According to the results, it was found that incorporating active additives decreased the storage modulus of the films and consequently, their elastic behaviour. This reduction was directly related to the molecular weight of the composite and the particle size. By increasing the amount of low molecular weight additives in the formulation of the film, $\mathrm{E}^{\prime}$ values decreased. Therefore, the sample containing $2 \% \mathrm{SA}$ with a molecular weight of $13.1 \mathrm{~g} \cdot \mathrm{mol}^{-1}$ and $3 \%$ BHA with a molecular weight of $160.3 \mathrm{~g} \cdot \mathrm{mol}^{-1}$ had higher $\mathrm{E}^{\prime}$ values (at temperature range of -40 to $150{ }^{\circ} \mathrm{C}$ ). The glass transition was also partly affected by the molecular weight [70]. Therefore, by decreasing molecular weight and by increasing the crystalline portion of composites, $\mathrm{Tg}, \mathrm{E}^{\prime \prime}$, and $\tan \delta$ were decreased (at temperatures below $47^{\circ} \mathrm{C}$ ) [68].

In the small amounts of additives in the PP matrix, they acted as a stabilizer and plasticizer, which reduced the $\mathrm{Tg}$ and also the melting point that was in agreement with findings of Byun et al. [27]. The results of Ortiz-Vazquez et al. [29] did not show any significant change in $\mathrm{Tg}$ by adding $1.5 \%$ BHT, and Jamshidian et al. [71] expressed no change in the melting point by adding $1 \%$ BHT to the PLA polymer matrix, while Goncalves et al. [67] depicted that the incorporation of antioxidants such as BHT and TBHQ to the PLA increased the free volume of the polymer matrix and consequently the chain mobility, hence $\mathrm{Tg}$, and the melting point decreased, which were in compliance with the results of this study. Overall, it seems that thermal and dynamic and mechanical properties of the active films were most affected by BHT. Therefore, the presence of BHT decreased the storage and loss modulus of the composite films. Moreover, the melting point of the BHT containing film $\left(\mathrm{T}_{2}\right)$ was significantly decreased compared to that of control $\left(\mathrm{T}_{1}\right)$. However, was better in the $\mathrm{T}_{4}$ sample made by combining the mixture of three additives, indicating the synergistic effect of the two antioxidants in the presence of antimicrobial agents on the thermal properties of active films.

\subsection{Film Transparency}

The UV-Vis pattern of the prepared films was illustrated in Figure 7A, (also, in Figure 7B, to show a better clarity at wavelength limit of $200-320 \mathrm{~nm}$ ). 


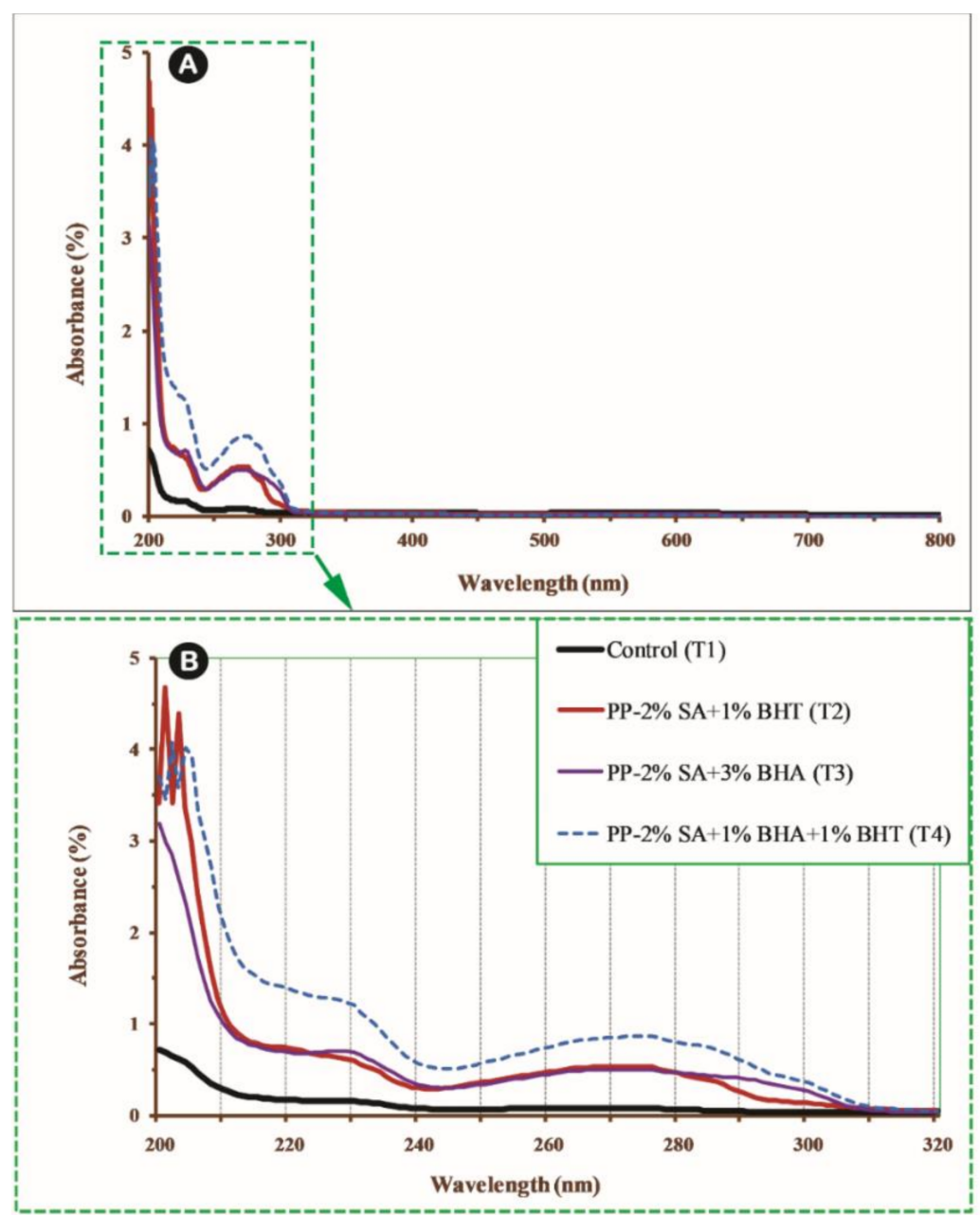

Figure 7. Effect of different composition of additives on UV absorbance of PP-based active films at wavelength range of $200-800 \mathrm{~nm}$ (A); the same results at wavelength range of 200-320 nm (B).

Control film ( $\mathrm{T}_{1}$, pure PP) did not show UV absorbance at wavelengths between $200 \mathrm{~nm}$ and $800 \mathrm{~nm}$ (Figure 7A). However, all active films displayed higher absorbance at wavelength between $200 \mathrm{~nm}$ and $300 \mathrm{~nm}$. The samples PP-2\%SA-1\%BHT $\left(\mathrm{T}_{2}\right)$ and PP$2 \%$ SA-3\%BHA $\left(\mathrm{T}_{3}\right)$ had almost similar UV absorbance at 200-300 nm (Figure 7B), while the sample PP-2\%SA-1\%BHT-1\%BHA $\left(\mathrm{T}_{4}\right)$ showed higher absorbance that could be explained by Beer-Lambert's law. The results of the comparison of transparency of the antioxidant and antimicrobial films are shown in Table 3. Incorporating SA and BHT into PP-matrix increased the transparency by about $5 \%$, while it was decreased for other samples; i.e., the transparency in the $\mathrm{T}_{4}$ was reduced by $9 \%$. We previously showed that PP-BHT films (at BHT concentrations of 1-3\%) had higher transparency values than PP-BHA films (at BHA concentrations of $1-3 \%$ ). It can be concluded that the higher absorbance of composite films, compared with that of control can be related to higher content of crystalline compounds [72], higher compatibility and uniform distribution of combined additives [45]. This reduced light transmission at a wavelength range of $200-300 \mathrm{~nm}$. Our data are in agreement with earlier reports on optical behaviour of BHT films [73], BHT and BHA in multilayer films (HDPE, EVOH and LDPE) [74] and gelatine-BHT films [45]. The migration of additives from the films is inevitable during storage period, because it should happen to provide antioxidant/antimicrobial effects in the food. There is a possibility that the migration phenomenon can affect the UV absorbance of the film samples, which should be taken into account. 
Table 3. The results of contact angle and the transparency of polypropylene (PP)-based active films.

\begin{tabular}{ccc}
\hline Film Samples & $\begin{array}{c}\text { Transparency } \\
\mathbf{( \% )}\end{array}$ & $\begin{array}{c}\text { Contact Angle } \\
\left(\boldsymbol{\theta}^{\circ}\right)\end{array}$ \\
\hline Pure PP (control) $\left(\mathrm{T}_{1}\right)$ & $76.80 \pm 0.001^{* \mathrm{~b}}$ & $100.15 \pm 2.20^{\mathrm{a}}$ \\
PP-2\%SA-1\%BHT $\left(\mathrm{T}_{2}\right)$ & $80.57 \pm 0.004^{\mathrm{a}}$ & $108.15 \pm 6.30^{\mathrm{a}}$ \\
PP-2\%SA-3\%BHA $\left(\mathrm{T}_{3}\right)$ & $75.23 \pm 0.007^{\mathrm{c}}$ & $107.24 \pm 1.67^{\mathrm{a}}$ \\
PP-2\%SA-1\%BHT-1\%BHA & $69.85 \pm 0.003^{\mathrm{d}}$ & $109.03 \pm 3.60^{\mathrm{a}}$ \\
$\left(\mathrm{T}_{4}\right)$ &
\end{tabular}

${ }^{*}$ Data are mean of triplicate measurements \pm SD. Different letters in superscripts in each column show significant $(p<0.05)$ differences between means.

\subsection{Contact Angle}

Contact angle $(\theta)$ is known as an angle between a solid and a liquid or the angle resulting from the fluid on the solid surface. It relates to the wettability of a film surface, which is significant and applicable feature of packaging films considering coatings and printing operations, as well as bacterial adhesion and cleanness of food contact surfaces. The contact angle of the films with a drop of distilled water was considered, and the results are shown in Table 3. The addition of SA, BHA, and BHA did not significantly $(p>0.05)$ change the contact angle, and thereby, the wettability of the composite films. The contact angle obtained for samples varied from $100.15^{\circ}$ to $109.03^{\circ}$, which the angle values more than $90^{\circ}$ indicated the dominance of the hydrophobic property, and thus, weak wettability of the prepared films [75]. The contact angle of pure PP was $100.15^{\circ}$. Higher contact angle is related to the nature of the hydrophobic polymeric matrix and a slight increased contact angle of the composite films is probably due to the incorporating hydrophobic and water insoluble additives such as SA, BHA and BHT [71].

\subsection{Colour Attributes}

The results of the colour attributes are shown in Table 4. Data indicated that there was no significant $(p>0.05)$ difference in brightness $\left(\mathrm{L}^{*}\right)$, redness $\left(\mathrm{a}^{*}\right)$, yellowness $\left(\mathrm{b}^{*}\right)$, total colour change $(\Delta \mathrm{E})$, yellowness $(\mathrm{YI})$, and whiteness $(\mathrm{WI})$ indices of composite active films as compared to those of the control. The lower amounts of additives used could account for this result. This was previously confirmed in the case of films prepared by incorporating SA into PP-based antimicrobial films [67].

Table 4. Colour attributes of different polypropylene (PP)-based active films.

\begin{tabular}{|c|c|c|c|c|c|c|}
\hline & $\mathrm{L}^{*}$ & $\mathrm{~A}^{*}$ & B * & $\Delta \mathrm{E}$ & YI & WI \\
\hline Pure PP (control) $\left(\mathrm{T}_{1}\right)$ & $63.7 \pm 0.61 * a$ & $-8.1 \pm 0.99 \mathrm{a}$ & $-4.8 \pm 1.25$ a & $6.4 \pm 1.04 \mathrm{a}^{\mathrm{a}}$ & $-3.2 \pm 0.86^{\mathrm{a}}$ & $60.5 \pm 0.58^{\mathrm{a}}$ \\
\hline PP- $2 \%$ SA- $1 \%$ BHT $\left(\mathrm{T}_{2}\right)$ & $62.3 \pm 1.46^{\mathrm{a}}$ & $-8.8 \pm 1.31 \mathrm{a}$ & $-5.7 \pm 2.72^{\mathrm{a}}$ & $6.7 \pm 2.64^{\mathrm{a}}$ & $-3.9 \pm 1.88 \mathrm{a}$ & $60.7 \pm 1.45^{a}$ \\
\hline PP-2\%SA-3\%BHA $\left(\mathrm{T}_{3}\right)$ & $63.2 \pm 0.60^{\mathrm{a}}$ & $-9.7 \pm 0.31 \mathrm{a}$ & $-4.7 \pm 0.23 \mathrm{a}$ & $6.6 \pm 0.16^{a}$ & $-3.2 \pm 0.18 \mathrm{a}$ & $61.6 \pm 0.53^{a}$ \\
\hline PP- $2 \%$ SA- $1 \%$ BHT- $1 \%$ BHA $\left(\mathrm{T}_{4}\right)$ & $62.9 \pm 0.50 \mathrm{a}$ & $-9.7 \pm 1.75 \mathrm{a}$ & $-2.2 \pm 1.59 \mathrm{a}$ & $6.6 \pm 1.72^{a}$ & $-1.5 \pm 1.11^{\mathrm{a}}$ & $61.5 \pm 0.36^{\mathrm{a}}$ \\
\hline
\end{tabular}

\subsection{Antioxidant Properties}

Table 5 demonstrates the antioxidant activity of pure PP film and the composite films containing different combinations of BHA, BHT, and SA. As can be seen in this table, DPPH radical scavenging activity of composite films $(62-91 \%)$ were significantly $(p<0.05)$ higher than that of pure PP film $(0.8 \%)$. Among different composite film samples, the antioxidant activity of $\mathrm{T}_{4}$ sample was the highest $(90.8 \%)$ followed by $\mathrm{T}_{2}(81.8 \%)$ and $\mathrm{T}_{3}$ $(62.5 \%)$ samples. Antioxidant efficiency and the thermal stability of synthetic antioxidants are different, which may play a role in the observed differences among different composite films. Commercial BHA is a mixture of mostly (90\%) 3-BHA (3-tert-butyl-4-hydroxyanisole) and a 10\% 2-BHA (2-tert-butyl-4-hydroxyanisole) molecules [76]. The tertiary butyl groups in BHA structure are subjected to different hydroxyl groups making steric barrier, which can lead to reduced antioxidant capacity of BHA, compared with BHT. The presence of such tertiary butyl groups in the BHA chemical structure may alter the antioxidant capacity 
of phenolic group [71]. It is reported that the butyl steric barrier and the prohibited phenol rings in BHA structure may account for its low thermal stability as well [77]. Overall, this could describe why BHA, containing composite films ( $\mathrm{T}_{3}$ sample), possesses lower antioxidant capacity, compared with BHT film ( $\mathrm{T}_{2}$ sample). Surprisingly, as reported in Table 5, composite film with a combination of BHT, BHA and SA exhibited the highest antioxidant activity (a DPPH-RSA value of $90.8 \%$ ). This can be probably explained by the possible synergism between BHA and BHT molecules, which has also been confirmed in earlier studies [78]. Besides, the presence of sorbic acid in $\mathrm{T}_{4}$ film can act as a hydrogen donor resulting the inhibition of free radicals, which has been confirmed by previous studies on the antioxidant action of organic acids [79]. Thus, incorporating SA in combination with BHT and BHA enhanced the antioxidant activity of the resulting composite film ( $\mathrm{T}_{4}$ sample).

Table 5. The results of antioxidant capacity expressed as 2,2-diphenyl-1-picrylhydrazyl (DPPH) radical scavenging activity (RSA), and antimicrobial properties of PP-based composite films incorporating a different combination of antioxidants/antimicrobials.

\begin{tabular}{|c|c|c|c|c|}
\hline \multirow{2}{*}{ Film Samples } & \multirow{2}{*}{$\begin{array}{c}\text { DPPH-RSA } \\
(\%)\end{array}$} & \multicolumn{3}{|c|}{ Microbial Analysis } \\
\hline & & $\begin{array}{c}\text { E. coli } \\
(\mathrm{Log} \mathrm{cfu} / \mathrm{mL})\end{array}$ & $\begin{array}{c}\text { S. aureus } \\
(\mathrm{Log} \mathrm{cfu} / \mathrm{mL})\end{array}$ & $\begin{array}{c}\text { A. niger } \\
\text { (Inhibition } \\
\text { Area, } \mathrm{cm}^{2} \text { ) }\end{array}$ \\
\hline Pure PP (control) $\left(\mathrm{T}_{1}\right)$ & $0.83 \pm 0.12 * \mathrm{~d}$ & $8.70 \pm 0.02^{\mathrm{a}}$ & $8.61 \pm 0.00^{\mathrm{a}}$ & 0 \\
\hline PP-2\%SA-1\%BHT $\left(\mathrm{T}_{2}\right)$ & $81.84 \pm 1.02^{b}$ & $8.41 \pm 0.01^{b}$ & $8.40 \pm 0.01^{b}$ & 0 \\
\hline $\begin{array}{c}\text { PP-2\%SA-3\%BHA }\left(\mathrm{T}_{3}\right) \\
\text { PP- } 2 \% \text { SA- } 1 \% \text { BHT- }\end{array}$ & $62.47 \pm 1.53^{c}$ & $8.38 \pm 0.01^{b c}$ & $8.38 \pm 0.00^{b}$ & 0 \\
\hline $\begin{array}{c}1 \% \mathrm{BHA} \\
\left(\mathrm{T}_{4}\right)\end{array}$ & $90.81 \pm 2.04^{a}$ & $8.35 \pm 0.01^{\mathrm{c}}$ & $8.20 \pm 0.01^{c}$ & 0 \\
\hline
\end{tabular}

\subsection{Antimicrobial Properties}

The results of microbial experiments of the active films against $E$. coli as gram negative, S. aureus as gram positive bacteria, and A. niger are shown in Table 5. All active film samples significantly $(p<0.05)$ retarded the growth of $E$. coli and $S$. aureus. Incorporating a $2 \%$ concentration of SA in the pure PP matrix reduced the E. coli and S. aureus counts from 8.70 to 8.56 and from 8.61 to $8.53\left(\log\right.$ cfu. $\mathrm{mL}^{-1}$ ), respectively (results are not shown here). As can be seen in Table 5, the addition of the same concentration of sorbic acid in combination with BHA and BHT was more effective than the addition of SA alone. This can be explained by the additional antimicrobial effect of BHT and BHA molecules, as also reported earlier [80]. The antibacterial activity of PP-2\%SA-1\%BHT-1\%BHA $\left(\mathrm{T}_{4}\right)$ sample against both bacteria was more enhanced, compared to PP-2\%SA-3\%BHA $\left(\mathrm{T}_{3}\right)$ and PP-2\%SA-1\%BHT $\left(\mathrm{T}_{2}\right)$ active films, due to the synergistic effect of BHT and BHA molecules with each other and with SA. Contrary to what we expected for the anti-mould action of sorbic acid, all active films did not show inhibitory zone in the inoculated A. niger cultures. A possible explanation could be the lower thickness of the film samples, in which they fail to release or propagate enough SA molecules into the mould culture to inhibit $A$. niger growth.

\subsection{Migration Analysis}

Table 6 shows the migration behaviour of composite films incorporating antimicrobial/antioxidants additives into different food simulants. The results presented in this table showed no significant differences $(p>0.05)$ in migration behaviour of all composite films in distilled water as simulant for aqueous foods. While, in acidic and fatty food simulants increasing both antioxidants concentration led to a significant $(p<0.05)$ increase in the migration values of the resulting films. Moreover, PP-3\%BHA and PP-3\%BHT samples ex- 
hibited higher migration values than other films in acidic and fatty food simulants. PP-films containing combination of additives at lower concentrations ( $T_{2}$ and $T_{4}$ samples), showed lower migration values. The composite films containing BHT showed higher migration values than films containing BHA. This may be explained by difference in their density $(\rho)$, molecular weight $(\mathrm{Mv})$, molecular volume $(\mathrm{Mv})$ and surface area. BHT with higher density $\left(1.048 \mathrm{~g} \cdot \mathrm{cm}^{-3}\right), \mathrm{Mw}\left(220.4 \mathrm{~g} \cdot \mathrm{mol}^{-1}\right), \mathrm{Mv}\left(256 \mathrm{~cm}^{3} \cdot \mathrm{mol}^{-1}\right)$, and surface area $\left(19.4 \times 10^{-9}\right.$ $\mathrm{cm}^{2} \cdot \mathrm{mol}^{-1}$ ) showed higher migration values compared to BHA with $\rho=1.009 \mathrm{~g} \cdot \mathrm{cm}^{-3}$, Mw $=180.3 \mathrm{~g} \cdot \mathrm{mol}^{-1}, \mathrm{Mv}=182.4 \mathrm{~cm}^{3} \cdot \mathrm{mol}^{-1}$, and surface area $=14.5 \times 10^{-9} \mathrm{~cm}^{2} \cdot \mathrm{mol}^{-1}$ [57]. Additives with higher $\mathrm{Mw}$ and $\mathrm{Mv}$ facilitated the movement of molecules within the polymeric chains, which this would increase their release rate to the simulants [29].

Table 6. Migration behaviour of composite films incorporating single or a combination of antimicrobial/antioxidant additives in aqueous, acidic and fatty food simulants.

\begin{tabular}{cccc}
\hline Film Samples & $\begin{array}{c}\text { Aqueous Foods } \\
(\mathbf{p H}>\mathbf{4 . 5})\end{array}$ & $\begin{array}{c}\text { Acidic Foods } \\
(\mathbf{p H} \leq 4.5)\end{array}$ & Fatty Foods \\
\hline Pure PP (control) $\left(\mathrm{T}_{1}\right)$ & $0.78 \pm 0.09^{* \mathrm{~b}}$ & $0.74 \pm 0.06^{\mathrm{d}}$ & $0.78 \pm 0.09 \mathrm{~g}$ \\
PP-2\% SA & $1.95 \pm 0.69^{\mathrm{a}}$ & $4.62 \pm 0.33^{\mathrm{a}}$ & $2.09 \pm 0.39^{\mathrm{f}}$ \\
PP-1\% BHT & $1.45 \pm 0.90^{\mathrm{a}}$ & $1.99 \pm 0.21^{\mathrm{c}}$ & $4.21 \pm 0.17^{\mathrm{e}}$ \\
PP-2\% BHT & $1.76 \pm 0.59^{\mathrm{a}}$ & $3.38 \pm 0.45^{\mathrm{b}}$ & $5.46 \pm 0.27^{\mathrm{d}}$ \\
PP-3\% BHT & $1.96 \pm 0.25^{\mathrm{a}}$ & $4.96 \pm 0.33^{\mathrm{a}}$ & $7.96 \pm 0.35^{\mathrm{a}}$ \\
PP-1\% BHA & $1.38 \pm 0.12^{\mathrm{a}}$ & $2.09 \pm 0.21^{\mathrm{c}}$ & $4.62 \pm 0.33^{\mathrm{e}}$ \\
PP-2\% BHA & $1.96 \pm 0.66^{\mathrm{a}}$ & $3.98 \pm 0.16^{\mathrm{b}}$ & $5.84 \pm 0.27^{\mathrm{d}}$ \\
PP-3\% BHA & $1.99 \pm 0.63^{\mathrm{a}}$ & $5.22 \pm 0.26^{\mathrm{a}}$ & $8.54 \pm 0.26^{\mathrm{a}}$ \\
PP-2\%SA-1\%BHT $\left(\mathrm{T}_{2}\right)$ & $2.32 \pm 0.39^{\mathrm{a}}$ & $2.12 \pm 0.23^{\mathrm{c}}$ & $6.37 \pm 0.30^{\mathrm{c}}$ \\
PP-2\%SA-3\%BHA $\left(\mathrm{T}_{3}\right)$ & $2.84 \pm 0.44^{\mathrm{a}}$ & $3.66 \pm 0.36^{\mathrm{b}}$ & $7.22 \pm 0.17^{\mathrm{b}}$ \\
PP-2\%SA-1\%BHT- & & & \\
1\%BHA & $2.43 \pm 0.50^{\mathrm{a}}$ & $2.36 \pm 0.28^{\mathrm{c}}$ & $6.64 \pm 0.16^{\mathrm{c}}$ \\
(T) & & & \\
\hline
\end{tabular}

* Data expressed as $\mathrm{mg} \cdot \mathrm{dm}^{-2}$ are average of triplicate measurements \pm standard deviations. Mean values with different letters in each column are significantly different $(p<0.05)$.

\section{Conclusions}

In this study, PP-based active films containing combined BHA, BHT and sorbic acid additives at different concentrations, were prepared and their physical, mechanical, thermal, structural, antioxidant and antimicrobial properties were investigated. FTIR spectroscopy revealed that the addition of BHT, BHA and SA into PP-matrix was in favour of physical interactions or mixing rather than formation of new chemical bonds or the deletion of existing functional groups. Therefore, the lack of chemical interactions between functional groups might facilitate the release of active antioxidant or antimicrobial agents from film body to the food surface. SEM demonstrated that PP-2\%SA-1\%BHT-1\%BHA $\left(\mathrm{T}_{4}\right)$ sample had the most homogenous dispersion of the particles among three active films, indicating that a combinatory use of these additives at low concentrations produced smooth film surface as the control film. In line with these observations, colour measurements also showed that incorporating antioxidant and antimicrobial additives did not significantly change the colour attributes of the active composite films compared to those of control. However, dynamic mechanical thermal analysis (DMTA) was mostly influenced by the presence of BHT in the composite films, leading reduced storage and loss moduli of the films; therefore, weak viscoelastic behaviour of the films, and lowered melting point. Moreover, the active films demonstrated higher tensile strength (TS) and lower elongation at break $\left(\mathrm{E}_{\mathrm{b}}\right)$ values compared to pure PP-film. It was observed that BHT and BHA in the presence of SA, increased and decreased the transparency of the active composite films, respectively. BHT films showed more UV absorbance than BHA films. The addition of SA, BHA and BHT did not significantly affect the contact angle, and thus, the wettability properties of the films. All active films had higher antioxidant and antimicrobial activities than those of pure PP-film. Active films significantly retarded gram-negative and gram- 
positive bacteria growth. Different properties of the prepared composite active films revealed their potential use for food packaging applications. In relation to the importance of expanding food shelf-life, and the negative impact of the direct application of preservatives on health, active composite PP films used in this study could be useful for food packaging applications suggesting $T_{2}$ and $T_{4}$ samples for cold packing (packaging of food products with low filling temperatures) due their lower thermal properties and $T_{3}$ film for hot packing (with high filling temperatures).

Author Contributions: Conceptualization, S.H.P.; formal analysis, S.H.F., S.J.P.; data curation: S.H.F.; writing—original draft preparation, S.H.F.; review and editing, S.H.P., M.P., R.D., J.M.L., supervision: S.H.P. All authors have read and agreed to the published version of the manuscript.

Funding: This research received no external funding.

Institutional Review Board Statement: Not applicable.

Informed Consent Statement: Not applicable.

Data Availability Statement: The data presented in this study are available in the article.

Acknowledgments: We acknowledge the financial support provided by University of Tabriz (Tabriz, Iran) in performing the PhD study reported in this paper. We thank Abdulrasoul Oromiehie (Islamic Azad University, Southern Tehran Branch, Tehran, Iran) for his excellent assistance and laboratory support.

Conflicts of Interest: The authors declare no conflict of interest.

\section{References}

1. Sarabandi, K.; Peighambardoust, S.H.; Mahoonak, A.R.S.; Samaei, S.P. Effect of different carriers on microstructure and physical characteristics of spray dried apple juice concentrate. J. Food Sci. Technol. 2018, 55, 3098-3109. [CrossRef]

2. Sarabandi, K.; Peighambardoust, S.H.; Mahoonak, A.S.; Samaei, S.P. Effect of carrier types and compositions on the production yield, microstructure and physical characteristics of spray dried sour cherry juice concentrate. J. Food Meas. Charact. 2017, 11, 1602-1612. [CrossRef]

3. Nottagh, S.; Hesari, J.; Peighambardoust, S.H.; Rezaei-Mokarram, R.; Jafarizadeh-Malmiri, H. Development of a biodegradable coating formulation based on the biological characteristics of the Iranian Ultra-filtrated cheese. Biologia 2018, 73, 403-413. [CrossRef]

4. Peighambardoust, S.J.; Peighambardoust, S.H.; Pournasir, N.; Mohammadzadeh Pakdel, P. Properties of active starch-based films incorporating a combination of $\mathrm{Ag}, \mathrm{ZnO}$ and $\mathrm{CuO}$ nanoparticles for potential use in food packaging applications. Food Packag. Shelf Life 2019, 22, 100420. [CrossRef]

5. Sakooei-Vayghan, R.; Peighambardoust, S.H.; Hesari, J.; Soltanzadeh, M.; Peressini, D. Properties of dried apricots pretreated by ultrasound-assisted osmotic dehydration and application of active coatings. Food Technol. Biotechnol. 2020, 58, 249-259. [CrossRef] [PubMed]

6. Sakooei-Vayghan, R.; Peighambardoust, S.H.; Hesari, J.; Peressini, D. Effects of osmotic dehydration (with and without sonication) and pectin-based coating pretreatments on functional properties and color of hot-air dried apricot cubes. Food Chem. 2020, 311, 125978. [CrossRef] [PubMed]

7. Türkoğlu, Ş. Genotoxicity of five food preservatives tested on root tips of Allium cepa L. Mutat. Res. Toxicol. Environ. Mutagenesis 2007, 626, 4-14. [CrossRef] [PubMed]

8. Fasihnia, S.H.; Peighambardoust, S.H.; Peighambardoust, S.J.; Oromiehie, A. Development of novel active polypropylene based packaging films containing different concentrations of sorbic acid. Food Packag. Shelf Life 2018, 18, 87-94. [CrossRef]

9. Alirezalu, K.; Pateiro, M.; Yaghoubi, M.; Alirezalu, A.; Peighambardoust, S.H.; Lorenzo, J.M. Phytochemical constituents, advanced extraction technologies and techno-functional properties of selected Mediterranean plants for use in meat products. A comprehensive review. Trends Food Sci. Technol. 2020, 100, 292-306. [CrossRef]

10. Leslie, S.W.; Gad, S.C.; Acosta, D. Cytotoxicity of butylated hydroxytoluene and butylated hydroxyanisole in cultured heart cells. Toxicology 1978, 10, 281-289. [CrossRef]

11. Kamemura, N. Butylated hydroxytoluene, a food additive, modulates membrane potential and increases the susceptibility of rat thymocytes to oxidative stress. Comput. Toxicol. 2018, 6, 32-38. [CrossRef]

12. Park, S.; Lee, J.-Y.; Lim, W.; You, S.; Song, G. Butylated hydroxyanisole exerts neurotoxic effects by promoting cytosolic calcium accumulation and endoplasmic reticulum stress in Astrocytes. J. Agric. Food Chem. 2019, 67, 9618-9629. [CrossRef]

13. Mahapatra, S.K.; Parija, S.C. Food additives: Potential risk for cancer. World J. Pharm. Res. 2018, 7, 405-410. [CrossRef]

14. Hajizadeh, H.; Peighambardoust, S.J.; Peighambardoust, S.H.; Peressini, D. Physical, mechanical, and antibacterial characteristics of bio-nanocomposite films loaded with Ag-modified $\mathrm{SiO}_{2}$ and $\mathrm{TiO}_{2}$ nanoparticles. J. Food Sci. 2020, 85, 1193-1202. [CrossRef] 
15. Khodaeimehr, R.; Peighambardoust, S.J.; Peighambardoust, S.H. Preparation and characterization of corn starch/clay nanocomposite films: Effect of clay content and surface modification. Starch/Stärke 2018, 70, 1700251. [CrossRef]

16. Nottagh, S.; Hesari, J.; Peighambardoust, S.H.; Rezaei-Mokarram, R.; Jafarizadeh-Malmiri, H. Effectiveness of edible coating based on chitosan and natamycin on biological, physico-chemical and organoleptic attributes of Iranian ultra-filtrated cheese. Biologia 2020, 75, 605-611. [CrossRef]

17. Peighambardoust, S.J.; Zahed-Karkaj, S.; Peighambardoust, S.H.; Ebrahimi, Y.; Peressini, D. Characterization of carboxymethyl cellulose-based active films incorporating non-modified and Ag or Cu-modified Cloisite 30B and montmorillonite nanoclays. Iran. Polym. J. 2020, 29, 1087-1097. [CrossRef]

18. Golshan Tafti, A.; Peighambardoust, S.H.; Hesari, J.; Bahrami, A.; Shakuoie Bonab, E. Physico-chemical and functional properties of spray-dried sourdough in breadmaking. Food Sci. Technol. Int. 2013, 19, 271-278. [CrossRef] [PubMed]

19. Fasihnia, S.H.; Peighambardoust, S.H.; Peighambardoust, S.J. Nanocomposite films containing organoclay nanoparticles as an antimicrobial (active) packaging for potential food application. J. Food Process. Preserv. 2017, 42, e13488. [CrossRef]

20. Golshan Tafti, A.; Peighardoust, S.H.; Behnam, F.; Bahrami, A.; Aghagholizadeh, R.; Ghamari, M.; Rafat, S.A. Effects of spray-dried sourdough on flour characteristics and rheological properties of dough. Czech J. Food Sci. 2013, 31, 361-367. [CrossRef]

21. Dehghan-Manshadi, A.; Peighambardoust, S.H.; Azadmard-Damirchi, S.; Niakosari, M. Effect of infrared-assisted spouted bed drying of flaxseed on the quality characteristics of its oil extracted by different methods. J. Sci. Food Agric. 2020, 100, 74-80. [CrossRef] [PubMed]

22. Dehghan-Manshadi, A.; Peighambardoust, S.H.; Azadmard-Damirchi, S.; Niakosari, M. Oxidative and physical stability, rheological properties and sensory characteristics of 'salad dressing' samples formulated with flaxseed oil and n-OSA starch. J. Food Meas. Charact. 2019, 13, 26-33. [CrossRef]

23. Dehghani, S.; Peighambardoust, S.H.; Peighambardoust, S.J.; Fasihnia, S.H.; Karimian Khosrowshahi, N.; Gullón, B.; Lorenzo, J.M. Optimization of the amount of $\mathrm{ZnO}, \mathrm{CuO}$, and $\mathrm{Ag}$ nanoparticles on antibacterial properties of low-density polyethylene (LDPE) films using the response surface method. Food Anal. Methods 2020. [CrossRef]

24. Ebrahimi, Y.; Peighambardoust, S.J.; Peighambardoust, S.H.; Zahed-Karkaj, S. Development of antibacterial carboxymethyl cellulose-based nanobiocomposite films containing various metallic nanoparticles for food packaging applications. J. Food Sci. 2019, 84, 2537-2548. [CrossRef]

25. Peighambardoust, S.H.; Beigmohammadi, F.; Peighambardoust, S.J. Application of organoclay nanoparticle in low-density polyethylene films for packaging of UF cheese. Packag. Technol. Sci. 2016, 29, 355-363. [CrossRef]

26. Dehghani, S.; Peighambardoust, S.H.; Peighambardoust, S.J.; Hosseini, S.V.; Regenstein, J.M. Improved mechanical and antibacterial properties of active LDPE films prepared with combination of Ag, ZnO and CuO nanoparticles. Food Packag. Shelf Life 2019, 22, 100391. [CrossRef]

27. Byun, Y.; Kim, Y.T.; Whiteside, S. Characterization of an antioxidant polylactic acid (PLA) film prepared with $\alpha$-tocopherol, BHT and polyethylene glycol using film cast extruder. J. Food Eng. 2010, 100, 239-244. [CrossRef]

28. Iheaturu, N.C.; Nwakaudu, A.A.; Nwakaudu, M.S.; Owuamanam, C.I. The use of natural antioxidant active polymer packaging for food preservation: A review. Futo J. Ser. 2018, 4, 94-112.

29. Ortiz-Vazquez, H.; Shin, J.; Soto-Valdez, H.; Auras, R. Release of butylated hydroxytoluene (BHT) from Poly(lactic acid) films. Polym. Test. 2011, 30, 463-471. [CrossRef]

30. Hauser, C.; Wunderlich, J. Antimicrobial packaging films with a sorbic acid based coating. Procedia Food Sci. 2011, 1, 197-202. [CrossRef]

31. Carocho, M.; Morales, P.; Ferreira, I.C. Antioxidants: Reviewing the chemistry, food applications, legislation and role as preservatives. Trends Food Sci. Technol. 2018, 71, 107-120. [CrossRef]

32. Wessling, C.; Nielsen, T.; Giacin, J.R. Antioxidant ability of BHT-and $\alpha$-tocopherol-impregnated LDPE film in packaging of oatmeal. J. Sci. Food Agric. 2001, 81, 194-201. [CrossRef]

33. Barbosa-Pereira, L.; Cruz, J.M.; Sendón, R.; De Quirós, A.R.B.; Ares, A.N.; Castro-López, M.; Abad, M.J.; Maroto, J.; PaseiroLosada, P. Development of antioxidant active films containing tocopherols to extend the shelf life of fish. Food Control 2013, 31, 236-243. [CrossRef]

34. De Dicastillo, C.L.; Castro-López, M.D.M.; López-Vilariño, J.M.; González-Rodríguez, M.V. Immobilization of green tea extract on polypropylene films to control the antioxidant activity in food packaging. Food Res. Int. 2013, 53, 522-528. [CrossRef]

35. Dong, Z.; Luo, C.; Guo, Y.; Ahmed, I.; Pavase, T.R.; Lv, L.; Li, Z.; Lin, H. Characterization of new active packaging based on PP/LDPE composite films containing attapulgite loaded with Allium sativum essence oil and its application for large yellow croaker (Pseudosciaena crocea) fillets. Food Packag. Shelf Life 2019, 20, 100320. [CrossRef]

36. Torres-Arreola, W.; Soto-Valdez, H.; Peralta, E.; Cárdenas-López, J.L.; Ezquerra-Brauer, J.M. Effect of a low-density polyethylene film containing butylated hydroxytoluene on lipid oxidation and protein quality of Sierra fish (Scomberomorus sierra) muscle during frozen storage. J. Agric. Food Chem. 2007, 55, 6140-6146. [CrossRef]

37. Soto-Cantú, C.; Graciano-Verdugo, A.; Peralta, E.; Islas-Rubio, A.; González-Córdova, A.; Gonzalez-Leon, A.; Soto-Valdez, H. Release of butylated hydroxytoluene from an active film packaging to Asadero cheese and its effect on oxidation and odor stability. J. Dairy Sci. 2008, 91, 11-19. [CrossRef]

38. Kuplennik, N.; Tchoudakov, R.; Zelas, Z.B.-B.; Sadovski, A.; Fishman, A.; Narkis, M. Antimicrobial packaging based on linear low-density polyethylene compounded with potassium sorbate. LWT 2015, 62, 278-286. [CrossRef] 
39. Fasihnia, S.H.; Peighambardoust, S.H.; Peighambardoust, S.J.; Oromiehie, A.; Soltanzadeh, M.; Peressini, D. Migration analysis, antioxidant, and mechanical characterization of polypropylene-based active food packaging films loaded with BHA, BHT, and TBHQ. J. Food Sci. 2020, 85, 2317-2328. [CrossRef]

40. Fasihnia, S.H.; Peighambardoust, S.H.; Peighambardoust, S.J.; Oromiehie, A.; Soltanzadeh, M.; Pateiro, M.; Lorenzo, J. Properties and application of multifunctional composite polypropylene-based films incorporating a combination of BHT, BHA and sorbic acid in extending donut shelf-life. Molecules 2020, 25, 5197. [CrossRef]

41. ASTM. ASTM D882-18, standard test method for tensile properties of thin plastic sheeting. In Annual Book of American Standard Testing Methods; American Society for Testing and Materials: West Conshohocken, PA, USA, 2018; Volume 8, pp. $182-190$.

42. Durmuş, A.; Woo, M.; Kaşgöz, A.; Macosko, C.W.; Tsapatsis, M. Intercalated linear low density polyethylene (LLDPE)/clay nanocomposites prepared with oxidized polyethylene as a new type compatibilizer: Structural, mechanical and barrier properties. Eur. Polym. J. 2007, 43, 3737-3749. [CrossRef]

43. Peighambardoust, S.H.; van Brenk, S.; van der Goot, A.J.; Hamer, R.J.; Boom, R.M. Dough processing in a Couette-type device with varying eccentricity: Effect on glutenin macro-polymer properties and dough micro-structure. J. Cereal Sci. 2007, 45, 34-48. [CrossRef]

44. Peighambardoust, S.H.; van der Goot, A.; Boom, R.; Hamer, R. Mixing behaviour of a zero-developed dough compared to a flour-water mixture. J. Cereal Sci. 2006, 44, 12-20. [CrossRef]

45. Jongjareonrak, A.; Benjakul, S.; Visessanguan, W.; Tanaka, M. Antioxidative activity and properties of fish skin gelatin films incorporated with BHT and $\alpha$-tocopherol. Food Hydrocoll. 2008, 22, 449-458. [CrossRef]

46. ASTM. ASTM D5026-15, Standard test methods for plastics: Dynamic mechanical properties: In tension. In Annual Book of American Standard Testing Methods; American Society for Testing and Materials: West Conshohocken, PA, USA, 2015.

47. Cook, W.D.; Scott, T.F.; Quay-Thevenon, S.; Forsythe, J.S. Dynamic mechanical thermal analysis of thermally stable and thermally reactive network polymers. J. Appl. Polym. Sci. 2004, 93, 1348-1359. [CrossRef]

48. Sun, C.-W.; Chuang, C.S.A.C. Hemodynamics study based on near-infrared optical assessment. Hemodyn. New Diagn. Ther. Approaches 2012, 3. [CrossRef]

49. Castejon, P.; Habibi, K.; Saffar, A.; Ajji, A.; Martínez, A.B.; Arencón, D. Polypropylene-based porous membranes: Influence of polymer composition, extrusion draw ratio and uniaxial strain. Polymer 2017, 10, 33. [CrossRef]

50. Williams, D.L.; Kuhn, A.T.; Amann, M.A.; Hausinger, M.B.; Konarik, M.M.; Nesselrode, E.I. Computerised measurement of contact angles. Galvanotechnik 2010, 101, 2502-2512.

51. Rhim, J.W.; Wu, Y.; Weller, C.L.; Schnepf, M. Physical characteristics of a composite film of soy protein isolate and propyleneglycol alginate. J. Food Sci. 1999, 64, 149-152. [CrossRef]

52. Karami, Z.; Peighambardoust, S.H.; Hesari, J.; Akbari-Adergani, B.; Andreu, D. Antioxidant, anticancer and ACE-inhibitory activities of bioactive peptides from wheat germ protein hydrolysates. Food Biosci. 2019, 32, 100450. [CrossRef]

53. Karami, Z.; Peighambardoust, S.H.; Hesari, J.; Akbari-Adergani, B.; Andreu, D. Identification and synthesis of multifunctional peptides from wheat germ hydrolysate fractions obtained by proteinase K digestion. J. Food Biochem. 2019, 43, e12800. [CrossRef]

54. Pezo, D.; Salafranca, J.; Nerín, C. Determination of the antioxidant capacity of active food packagings by in situ gas-phase hydroxyl radical generation and high-performance liquid chromatography-fluorescence detection. J. Chromatogr. A 2008, 1178, 126-133. [CrossRef] [PubMed]

55. BS-British-Standard. Part 1: Guide to the selection of conditions and test methods for overall migration. In Materials and Articles in Contact with Foodstuff-Plastics; BSI-British Standards Institution: London, UK, 2002; pp. 1-50.

56. Jamshidian, M.; Tehrany, E.A.; Desobry, S. Release of synthetic phenolic antioxidants from extruded poly lactic acid (PLA) film. Food Control 2012, 28, 445-455. [CrossRef]

57. Razali, I.; Nor Asimiah, A.S.; Norhaya, H. Determination of antioxidants in palm oil products by high performance liquid chromatography. Elaeis 1997, 9, 25-33.

58. Ammawath, W.; Man, Y.B.C.; Rahman, R.B.A.; Baharin, B.S. A fourier transform infrared spectroscopic method for determining butylated hydroxytoluene in palm olein and palm oil. J. Am. Oil Chem. Soc. 2006, 83, 187-191. [CrossRef]

59. Kang, K.; Chang, Y.; Choi, J.C.; Park, S.-J.; Han, J. Migration study of butylated hydroxytoluene and Irganox 1010 from polypropylene treated with severe processing conditions. J. Food Sci. 2018, 83, 1005-1010. [CrossRef]

60. Chinna Babu, P.; Sundaraganesan, N.; Dereli, Ö.; Türkkan, E. FT-IR, FT-Raman spectra, density functional computations of the vibrational spectra and molecular geometry of butylated hydroxy toluene. Spectrochim. Acta Part. A Mol. Biomol. Spectrosc. 2011, 79, 562-569. [CrossRef]

61. Trivedi, M.K.; Branton, A.; Trivedi, D.; Nayak, G.; Singh, R.; Jana, S. Physicochemical and spectroscopic characterization of biofield treated butylated hydroxytoluene. J. Food Ind. Microbiol. 2015, 1, 1.

62. Li, L.; Wang, H.; Chen, M.; Jiang, S.; Jiang, S.; Li, X.; Wang, Q. Butylated hydroxyanisole encapsulated in gelatin fiber mats: Volatile release kinetics, functional effectiveness and application to strawberry preservation. Food Chem. 2018, 269, 142-149. [CrossRef]

63. Pavia, D.L.; Lampman, G.M.; Kriz, G.S.; Vyvyan, J.A. Infrared spectroscopy. In Introduction to Spectroscopy; Pavia, D.L., Lampman, G.M., Kriz, G.S., Vyvyan, J.A., Eds.; Cengage Learning: Belmont, CA, USA, 2008; pp. 13-101. ISBN 1111800626.

64. Roeges, N.P.G. Normal vibrations and absorption regions of- $\mathrm{CH}_{2} \mathrm{X}$. In A guide to the Complete Interpretation of Infrared Spectra of Organic Structures; Roeges, N.P.G., Baas, J.M.A., Eds.; John Wiley \& Sons: New York, NY, USA, 1994; pp. 50-112. ISBN 0471939986. 
65. Mirghani, M.E.S.; Man, Y.B.C.; Jinap, S.; Baharin, B.S.; Bakar, J. A new method for determining aflatoxins in groundnut and groundnut cake using fourier transform infrared spectroscopy with attenuated total reflectance. J. Am. Oil Chem. Soc. 2001, 78, 985-992. [CrossRef]

66. Singh, S.; Lee, M.H.; Park, I.; Shin, Y.J. Antimicrobial properties of polypropylene films containing AgSiO2, AgZn and AgZ for returnable packaging in seafood distribution. J. Food Meas. Charact. 2016, 10, 781-793. [CrossRef]

67. Goncalves, C.M.B.; Tomé, L.C.; Garcia, H.; Brandão, L.; Mendes, A.M.; Marrucho, I.M. Effect of natural and synthetic antioxidants incorporation on the gas permeation properties of poly(lactic acid) films. J. Food Eng. 2013, 116, 562-571. [CrossRef]

68. Menard, K.P.; Menard, N.R. Dynamic Mechanical Analysis in the Analysis of Polymers and Rubbers. In Encyclopedia of Polymer Science and Technology; Wiley: New York, NY, USA, 2015; pp. 1-33.

69. Idicula, M.; Malhotra, S.; Joseph, K.; Thomas, S. Dynamic mechanical analysis of randomly oriented intimately mixed short banana/sisal hybrid fibre reinforced polyester composites. Compos. Sci. Technol. 2005, 65, 1077-1087. [CrossRef]

70. Hwang, S.W.; Shim, J.K.; Selke, S.E.; Soto-Valdez, H.; Matuana, L.; Rubino, M.; Auras, R. Poly(L-lactic acid) with added $\alpha$-tocopherol and resveratrol: Optical, physical, thermal and mechanical properties. Polym. Int. 2012, 61, 418-425. [CrossRef]

71. Jamshidian, M.; Tehrany, E.A.; Cleymand, F.; Leconte, S.; Falher, T.; Desobry, S. Effects of synthetic phenolic antioxidants on physical, structural, mechanical and barrier properties of poly lactic acid film. Carbohydr. Polym. 2012, 87, 1763-1773. [CrossRef]

72. Ramis-Ramos, G. Antioxidants I Synthetic antioxidants. In Encyclopedia of Food Sciences and Nutrition; Caballero, B., Ed.; Academic Press: Cambridge, UK, 2003; pp. 265-275.

73. Allen, N.; Fatinikun, K.; Henman, T. Influence of transition metal ions on the photo-behaviour of BHT in polypropylene: A uv-study. Polym. Degrad. Stab. 1987, 17, 81-88. [CrossRef]

74. Granda-Restrepo, D.; Peralta, E.; Troncoso-Rojas, R.; Soto-Valdez, H. Release of antioxidants from co-extruded active packaging developed for whole milk powder. Int. Dairy J. 2009, 19, 481-488. [CrossRef]

75. Zhuang, H.; Tang, N.; Yuan, Y. Purification and identification of antioxidant peptides from corn gluten meal. J. Funct. Foods 2013, 5, 1810-1821. [CrossRef]

76. Sun, Z.; Yang, X.; Liu, Q.S.; Li, C.; Zhou, Q.; Fiedler, H.; Liao, C.; Zhang, J.; Jiang, G. Butylated hydroxyanisole isomers induce distinct adipogenesis in 3T3-L1 cells. J. Hazard. Mater. 2019, 379, 120794. [CrossRef]

77. Borsato, D.; Cini, J.R.D.M.; Da Silva, H.C.; Coppo, R.L.; Angilelli, K.G.; Moreira, I.; Maia, E.C.R. Oxidation kinetics of biodiesel from soybean mixed with synthetic antioxidants BHA, BHT and TBHQ: Determination of activation energy. Fuel Process. Technol. 2014, 127, 111-116. [CrossRef]

78. Senanayake, S.N.; Wanasundara, P.J.P.; Shahidi, F. Antioxidants: Science, Technology, and Applications. In Bailey's Industrial Oil and Fat Products; Shahidi, F., Ed.; Wiley: Hoboken, NJ, USA, 2020; pp. 1-61.

79. Allam, S.S.M.; Mohamed, H.M.A. Thermal stability of some commercial natural and synthetic antioxidants and their mixtures. J. Food Lipids 2002, 9, 277-293. [CrossRef]

80. Fernández-Álvarez, L.; Del Valle, P.; De Arriaga, D.; García-Armesto, M.R.; Rúa, J. Binary combinations of BHA and other natural and synthetic phenolics: Antimicrobial activity against Staphylococcus aureus and antioxidant capacity. Food Control 2014, 42, 303-309. [CrossRef] 